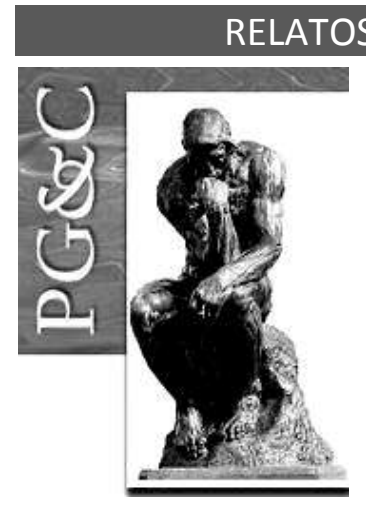

\title{
A GESTÃO DO CONHECIMENTO HOLÍSTICA: CONFORMAÇÃO DE SUAS DIMENSÕES
}

\author{
Fabio Corrêa \\ Doutor em Sistemas de Informação e Gestão do Conhecimento pela \\ Fundação Mineira de Educação e Cultura, Brasil. Professor da Universidade \\ do Estado de Minas Gerais, Brasil. \\ E-mail: fabiocontact@gmail.com \\ Leandro Cearenço Lima \\ Mestre em Sistemas de Informação e Gestão do Conhecimento pela \\ Fundação Mineira de Educação e Cultura, Brasil. \\ E-mail: leandrolima.panamericano@gmail.com \\ Fabrício Ziviani \\ Doutor em Ciência da Informação pela Universidade Federal de Minas \\ Gerais, Brasil. Professor da Fundação Mineira de Educação e Cultura, Brasil. \\ E-mail: contato@fabricioziviani.com.br \\ Jurema Suely de Araújo Nery Ribeiro \\ Doutoranda em Sistemas de Informação e Gestão do conhecimento pela \\ Fundação Mineira de Educação e Cultura, Brasil. Professora da \\ Universidade Pontifícia Universidade Católica de Minas Gerais, Brasil. \\ E-mail: jurema.nery@gmail.com

\section{Renata de Souza França} \\ Doutoranda em Sistemas de Informação e Gestão do conhecimento pela \\ Fundação Mineira de Educação e Cultura, Brasil. Professora da \\ Universidade do Estado de Minas Gerais, Brasil. \\ E-mail: profrenatafranca@gmail.com
}

\begin{abstract}
Resumo
Ao longo do percurso da Gestão do Conhecimento, diversos estudos foram desenvolvidos. Nessa trajetória há sinalizações de que os modelos de Gestão do Conhecimento sejam desenvolvidos e amparados no paradigma holístico. Alicerçado nessa perspectiva, esta pesquisa tem como objetivo conformar (identificar e consolidar) as dimensões que compõem a Gestão do Conhecimento rumo a uma abordagem holística. Por meio de procedimentos metodológicos de abordagem qualitativa, técnica de pesquisa bibliográfica e exame dos dados pela Análise de Conteúdo, esse estudo promoveu o atingimento do objetivo proposto. Por resultados são apresentadas as dimensões estratégia, liderança e suporte da alta administração, equipe de gestão do conhecimento, recursos (financeiro, humano, material e tempo), processos e atividades, gestão de recursos humanos, treinamento e educação, motivação, trabalho em equipe, cultura, tecnologia da informação, mensuração e projeto piloto da Gestão do Conhecimento holística. Conclui -se que essas dimensões tendem a beneficiar novas propostas de modelos de Gestão do Conhecimento, concernentes ao paradigma holístico, para que as contemplem de modo a prover uma gestão efetiva do conhecimento organizacional.
\end{abstract}

Palavras-chave: Gestão do Conhecimento. Paradigma holístico. Gestão do Conhecimento holística. Dimensões. Dimensões da Gestão do Conhecimento holística.

Perspectivas em Gestão \& Conhecimento, João Pessoa, v. 9, n. 2, p. 174-202, maio/ago. 2019. DOI: http://dx.doi.org/10.21714/2236-417X2019v9n2p174

http://periodicos.ufpb.br/ojs2/index.php/pgc. ISSN: 2236-417X. Publicação sob Licença (cc) EY-Nc-ND 


\title{
THE HOLISTIC KNOWLEDGE MANAGEMENT: CONFORMING THEIR DIMENSIONS
}

\begin{abstract}
Throughout the course of the Knowledge Management, several studies have been developed. In this trajectory, there are signs that the models from Knowledge Management are developed and supported in the holistic paradigm. Based on this perspective, this research aims to conform (identify and consolidate) the dimensions that compose the Knowledge Management for a holistic approach. Through methodological procedures of qualitative approach, bibliographic research technique and data analysis by Content Analysis, this study promoted the achievement of the proposed aim. The results are presented as strategic dimensions, leadership and support of the top directorship, knowledge management, resources (financial, human, material and temporal), processes and activities, human resource management, training and education, motivation, teamwork, culture, information Technology, measurement and pilot project of holistic knowledge management. Conclude that these dimensions tend to benefit new proposals from Knowledge Management models, regarding the holistic paradigm, to contemplate them, in order to provide effective management of the organizational knowledge.
\end{abstract}

Keywords: Knowledge management. Holistic paradigm. Holistic Knowledge Management. Dimensions. Dimensions of holistic Knowledge Management.

\section{INTRODUÇÃO}

A Gestão do Conhecimento (GC) é uma disciplina com aproximadamente 22 anos (BOLISANI; HANDZIC, 2015) que se decompõe em partes, denominadas dimensões. Essas dimensões podem ser entendidas como Fatores Críticos e Sucesso, sendo áreas das quais, se os resultados forem satisfatórios, garantirão desempenho organizacional (ROCKART, 1979). Algumas dessas dimensões são estratégia, liderança e suporte da alta administração, gestão de recursos humanos, motivação, tecnologia, cultura e mensuração, apresentadas nos modelos de Terra (2005a), Batista (2012) e Salzano et al. (2016).

Além de ser decomposta em partes a GC também atua em um ambiente organizacional fracionado. As empresas se subdividem em organogramas, setores e áreas, partes essas que abrigam pessoas especialistas, também segmentadas em funções e cargos (FERREIRA, 2009). As instituições de ensino, campo de estudo da GC (SÁNCHEZ; PONJUÁN DANTE, 2016; BEM; COELHO; DANDOLINI, 2016), também assumem a secção do ambiente organizacional e vão além. As fragmentações no ensino "[...] repartiram o conhecimento em áreas, as áreas em cursos, os cursos em disciplinas, as disciplinas em especificidades" (BEHRENS, 1999, p. 384).

Esse processo fragmentador é alicerçado no paradigma newtoniano-cartesiano, também denominado reducionismo (WEIL, 1991). Um paradigma, delineia instrumentos científicos metodológicos para se fazer ciência mediante aos problemas em análise (KUHN, 1998). Assim, o paradigma newtoniano-cartesiano promove a divisão do fenômeno em menores partes para que essas possam ser entendidas isoladamente, levando a posterior compreensão do fenômeno em questão (PEREIRA, 2002, MACIEL; SILVA, 2008; CREMA, 2015).

Weil (1991), Pereira (2002), Maciel e Silva (2008) e Crema (2015) sinalizam que o paradigma reducionista não mais é suficiente para tratar os problemas da atualidade, pois as problemáticas atuais são mais complexas do que as estudados no passado. Assim, emerge o paradigma holístico como uma alternativa que busca a complementação da teoria reducionista (CREMA, 1991; VERGARA, 1993). Esse paradigma busca recontextualizar as partes em um molde que contemple a totalidade (PEREIRA, 2002). Em outros termos, resulta em analisar as

Perspectivas em Gestão \& Conhecimento, João Pessoa, v. 9, n. 2, p. 174-202, maio/ago. 2019. 
partes não isoladamente, mas sim dentro de contexto para que as interligações entre as partes sejam mantidas de forma a constituir um único todo (CAPRA, 2000; PEREIRA, 2002).

A academia tem anunciado que a GC demanda de abordagens holísticas. Esse anuncio é posto como resultados dos estudos de Holsapple e Joshi (1999), Rubenstein-Montano et al. (2001), Heisig (2009) e Fteimi (2015), sobre um total de 270 modelos de GC. Tais modelos são representações esquemáticas que elucidam os elementos principais da GC e suas interfaces (WEBER, 2002) e visam orquestrar as partes da GC. O paradigma holístico para a GC pode ser visto como uma busca pela análise da GC (todo) mediante as suas partes (dimensões), analisadas em conjunto e não de forma disjunta.

Desse modo, a GC holística é um ajustamento do gerenciamento do conhecimento ao paradigma holístico, que anuncia que as partes - dimensões - dessa forma de gestão devem ser analisadas em conjunto (HEISIG, 2009; FTEIMI, 2015) para que se atinja uma gestão efetiva do conhecimento organizacional.

No entanto, quais são as partes que compõem a GC holística? Esse questionamento emerge como um problema de pesquisa a ser tratado nesse estudo e se justifica pela máxima de que "[...] 'Só posso compreender um todo se conheço, especificamente, as partes, mas só posso compreender as partes se conhecer o todo'” (MORIN, 2005, p. 181). Portanto, esse artigo tem por objetivo conformar (identificar e consolidar) as dimensões que compõem a GC rumo a uma abordagem holística.

Visando atingir o objetivo almejado e responder a problemática anunciada, a pesquisa se subdivide em partes, além dessa introdução (1). Na seção seguinte (2) são apresentados os procedimentos metodológicos empregados para o desenvolvimento do estudo. Em sequência (3) os resultados são explicitados, e posteriormente, são expostas as considerações finais (4) acerca da pesquisa. Por fim, as referências utilizadas no estudo são listadas e os apêndices, contendo os passos galgados nos procedimentos metodológicos são apresentados.

\section{METODOLOGIA}

Esta pesquisa é exploratória, se classifica pela abordagem qualitativa e emprega a técnica de pesquisa bibliográfica, fazendo uso da Análise de Conteúdo para examinar os dados. Por permitir captar significações a respeito do fenômeno estudado (MINAYO, 1998; GIL, 2002) a abordagem qualitativa foi determinada devido a necessidade de identificar e homogeneizar as dimensões da GC holística a partir da leitura de produções cientificas resultantes da pesquisa realizada.

A pesquisa bibliográfica faz uso de artigos, teses, dissertações e outras mídias (BARROS; LEHFELD, 2007) sendo, portanto, pertinente para o estudo o que outros pesquisadores ponderam sobre determinado assunto (MASCARENHAS, 2012), pois "[...] propicia o exame de um tema sob novo enfoque ou abordagem" (MARCONI; LAKATOS, 2003, p. 183). Nessa pesquisa, foram considerados artigos científicos como insumos da pesquisa bibliográfica.

Para o exame dos artigos científicos foi feito o uso da Análise de Conteúdo (BARDIN, 1977) que "[...] consiste em desmontar a estrutura e os elementos desse conteúdo para esclarecer suas diferentes características e extrair sua significação" (LAVILLE; DIONNE, 1999, p. 214), tendo por insumo textos escritos, passíveis de serem manipulados, para fornecer respostas a pergunta de pesquisa (GASKELL; BAUER, 2002).

Mediante ao delineamento metodológico adotado, a coleta de dados foi determinada de forma a permitir sua replicabilidade. Primando pelo rigor científico, os processos realizados para a constituição do corpus de estudos a serem analisados foi adotado um protocolo de estratégia de pesquisa, fundamentado na ótica de Dresch, Lacerda, Antunes Jr. (2015), exposto no Quadro 1.

Perspectivas em Gestão \& Conhecimento, João Pessoa, v. 9, n. 2, p. 174-202, maio/ago. 2019. 
Fábio Corrêa et al.

Quadro 1 - Protocolo de estratégia de pesquisa

\begin{tabular}{|c|c|}
\hline Protocolo & Descrição \\
\hline Quadro conceitual & $\begin{array}{l}\text { Os Fatores Críticos de Sucesso são imperativos nas tratativas relacionadas ao } \\
\text { conhecimento e determinam as áreas que essa temática deve abordar. Assim, } \\
\text { busca-se identificar estes fatores e compreendê-los teoricamente. }\end{array}$ \\
\hline Contexto & $\begin{array}{l}\text { Estudos que se propõem a apresentar os Fatores Críticos de Sucesso } \\
\text { relacionados a GC. }\end{array}$ \\
\hline Horizonte & Sem delimitação temporal. \\
\hline Correntes teóricas & $\begin{array}{l}\text { Fatores Críticos de Sucesso delimitam especificidades a serem consideradas } \\
\text { nas investidas em GC e são objeto de estudo em pesquisas que visam } \\
\text { identificá-los, avaliá-los ou relacioná-los diante da literatura ou pela percepção } \\
\text { de indivíduos entrevistados. Esse estudo considera como aderente ao seu } \\
\text { intento apenas pesquisas que fundamentam teoricamente tais fatores. }\end{array}$ \\
\hline Línguas & Inglês, espanhol e português \\
\hline $\begin{array}{l}\text { Critérios de } \\
\text { exclusão }\end{array}$ & $\begin{array}{l}\text { 1. Estudos indisponíveis para download; } \\
\text { 2. Estudos que não contenham os descritores no título; } \\
\text { 3. Estudos duplicados; } \\
\text { 4. Estudos que não fundamentam teoricamente os Fatores Críticos de } \\
\text { Sucesso apresentados. }\end{array}$ \\
\hline $\begin{array}{l}\text { Descritores (termos } \\
\text { de pesquisa) }\end{array}$ & $\begin{array}{l}\text { Termos presentes no título com operador booleano "and": "knowledge } \\
\text { management" e "critical success factors". }\end{array}$ \\
\hline Pesquisar fontes & SCOPUS \\
\hline
\end{tabular}

Fonte: Autores da pesquisa, adaptado de Dresch, Lacerda, Antunes Jr. (2015, p.142).

As dimensões da GC holística foram pautadas pela busca de Fatores Críticos de Sucesso da GC, pois esses podem ser compreendidos como áreas das quais, se os resultados forem satisfatórios, garantirão o desempenho organizacional bem-sucedido (ROCKART, 1979). Portanto, são áreas imperativas para o desenvolvimento da GC.

Para obtenção dos estudos, foi selecionada a base SCOPUS por ser essa "[...] considerada uma das principais referências internacionais em pesquisa pela sociedade científica brasileira" (OSINSKI; ROMAN; SELIG, 2015, p. 154). A busca foi realizada, precisamente, em 12/08/2017 as 07:05, pelos termos "knowledge management" e "critical success factors", se valendo do conector lógico booleano "and". Por resultado 48 produções acadêmicas, entre revisões de literatura, artigos de conferências e periódicos foram obtidas, sendo 8 não localizadas para download (critério de exclusão 1), restando 40 produções científicas.

As 40 produções literárias apresentaram os descritores de pesquisa no título (critério de exclusão 2) e foi identificado 1 estudo duplicado (critério de exclusão 3). Diante do intento de promover um entendimento teórico desses Fatores Críticos de Sucesso, os 39 estudos restantes foram lidos integralmente e 24 foram desconsiderados, uma vez que mencionam tais fatores ou aferem a percepção desses em pesquisas, mas não os fundamentam teoricamente (critério de exclusão 4). As referências mencionadas na aplicação de cada critério de exclusão são relacionadas no Apêndice I.

Por conseguinte, 15 estudos constituem a amostra pesquisada, a saber: Wong (2005b), Akhavan, Jafari e Fathian (2006), Lin e Lin (2006), Al-Mabrouk (2006), Gai e Xu (2009), Valmohammadi (2010), Altaher (2010), Abbaszadeh, Ebrahimi e Fotouhi (2010), Wai, Hong e Din (2011), Sedigui e Zand (2012), Anggia et al. (2013), Naghavi, Dastaviz e Nezakati (2013), Arif e Shalhoub (2014), Zieba e Zieba (2014) e Kumar, Singh e Haleem (2015).

As publicações de Skyrme e Amidon (1997) Davenport, De Long e Beers (1998) e Wong e Aspinwall (2005) foram adicionadas por serem frequentemente citadas pela literatura

Perspectivas em Gestão \& Conhecimento, João Pessoa, v. 9, n. 2, p. 174-202, maio/ago. 2019. 
analisada, totalizando a amostra em 18 publicações que tratam os Fatores Críticos de Sucesso, conforme protocolo de pesquisa, representando o traço temporal de 1997 a 2015.

Diversos Fatores Críticos de Sucesso foram identificados no corpus analisado (Apêndice II e III). Mediante ao entendimento semântico desses fatores, por meio da Análise de Conteúdo, os mesmos foram consolidados, constituindo 13 dimensões críticas para o sucesso da GC holística. Tais fatores são apresentados na seção seguinte.

\section{RESULTADOS}

Morin (2005) acena que só se pode compreender o todo quando se conhece as partes. Uma vez que se conhece o todo, ou seja, a GC holística, para delimitar suas partes (dimensões) esse estudo faz uso dos Fatores Críticos de Sucesso da GC, pois são áreas das quais, se os resultados forem satisfatórios, garantirão o desempenho organizacional bem-sucedido (ROCKART, 1979). Assim, as 13 dimensões da GC holística são descriminadas nas subseções seguintes.

\subsection{Estratégia}

A estratégia é um termo deliberadamente utilizado e possuidor de inúmeras definições (NICOLAU, 2001; LACERDA; ENSSLIN; ENSSLIN, 2002; OLIVEIRA, 2004). Para além das escolas estratégicas e do ponto de vista que tipifica e define a estratégia como plano, padrão, posição, perspectiva ou manobra (MINTZBERG; AHLSTRAND; LAMPEL, 2010), no contexto desse estudo, se faz necessário, o uso de uma caracterização para relacionar esse campo à GC holística.

O termo "caracterização" é utilizado de forma intencional para tornar claro que não se pretende lançar um novo conceito de estratégia, mas uma forma de visualizar esse campo e sua relação com a GC por meio das menções literárias que coligam estas duas temáticas.

Mediante conceitos relacionados por Nicolau (2001), a estratégia pode ser então caracterizada como a determinação de objetivos (CHANDLER, 1962) e planos para seu atingimento (LEARNED et al., 1965), a serem realizados por meio de ações (KATZ, 1970; QUINN, 1980) ofensivas ou defensivas (PORTER, 1980), com vistas a estabelecer um prospecto do futuro da organização (RAMANANTSOA, 1984) e conduzi-la rumo ao ambicionado, havendo de se considerar o meio no qual a empresa se situa (HOFER; SCHANDEL, 1978; JAUCH; GLUECK, 1980; MINTZBERG, 1988).

Por outros termos, consiste em uma visão que reflete o estado atual e o almejado pela organização, e resulta em um processo reflexivo quanto ao futuro a ser atingido, sustentado por metas e objetivos de longo prazo (DAVENPORT; PRUSAK, 1998; BUENO et al., 2004), incidindo na necessidade de planejamento.

O planejamento estratégico contempla a estratégia, seus objetivos e ações, e pode ser visto como uma forma da organização definir sua estratégia, ou direção, e tomar decisões sobre a alocação de seus recursos para atingimento do almejado (ALTAHER, 2010). Neste âmbito, a GC se relaciona com a estratégia sob duas perspectivas: clarificação e alinhamento.

$\mathrm{Na}$ perspectiva de clarificação, uma estratégia clara e bem definida é vital a GC (WONG; ASPINWALL, 2005; JUNIOR; POLIZEL; SILVA, 2012) para que esta se posicione no presente e permita comparações de sua evolução no futuro (ABBASZADEH; EBRAHIMI; FOTOUHI, 2010).

Uma vez estabelecida a estratégia da GC, essa deve ser compartilhada com os membros da organização, de forma que cada funcionário compreenda os objetivos a serem atingidos e atividades a desempenhar diante da proposta da GC (LIN, LIN, 2006; GAI; XU, 2009). Assim, a clarificação da estratégia da GC à organização visa criar um senso de paixão e

Perspectivas em Gestão \& Conhecimento, João Pessoa, v. 9, n. 2, p. 174-202, maio/ago. 2019. 
crença de que esta é passível de ser alcançada, permitindo assim a sua busca efetiva pela gerência e funcionários rumo ao almejado pela GC (WONG, 2005b).

Por outro viés, a estratégia de negócio deve estar alinhada à estratégia da GC (AKHAVAN; JAFARI; FATHIAN, 2006). As organizações possuem metas e objetivos particulares intrinsecamente relacionados ao seu negócio e estabelecem suas estratégias de forma a atingir o almejado. O programa de GC deve apoiar os objetivos do negócio por meio de uma proposta de valor (AL-MABROUK, 2006) como "melhor atendimento aos clientes" ou "produtos mais direcionados", ainda que o valor não possa ser calculado diretamente (SKYRME; AMIDON, 1997).

A GC é parte integrante da estratégia da empresa, para que o conhecimento seja utilizado de forma a prover obtenção de vantagem competitiva e os objetivos e metas organizacionais tendem a estabelecer uma ligação direta e firme com os propósitos do conhecimento para a empresa (WONG; ASPINWALL, 2005; SEDIGHI; ZAND, 2012).

Portanto, em relação a esse Fator Crítico de Sucesso é necessário estabelecer uma estratégia de GC alinhada à estratégia organizacional e clarifica-la para que toda a organização compreenda os objetivos almejados e acredite que as metas possam ser alcançadas, visando assim unicidade dos membros da organização rumo ao pretendido pelo planejamento realizado.

\subsection{Liderança e suporte da alta administração}

Os líderes devem atuar como modelos não somente por palavras, mas por meio de atos e exemplos a serem desempenhados pelos demais membros (GAI, XU, 2009; VALMOHAMMADI, 2010; WAI; HONG; DIN, 2011) e apoiar a GC em diversos fatores além do financeiro, criando assim condições para o desenvolvimento da GC (GAI, XU, 2009). Para Wong e Aspinwall (2005) e Junior, Poliezel e Silva (2012) a liderança assume papel influenciador no comportamento das pessoas para com a GC.

Visando apoiar a equipe de GC, a liderança deve compreender o conceito de GC e incentivar suas atividades (ZIEBA; ZIEBA, 2014), contribuindo para a homogeneização da mensagem quanto ao propósito do gerenciamento do conhecimento, bem como prover apoio moral e ações fomentadoras para uma cultura propícia ao compartilhamento do conhecimento (AL-MABROUK, 2006) e para um ambiente de criação de conhecimento e aprendizagem (WONG; ASPINWALL, 2005).

O sucesso de programas organizacionais deve possuir apoio do Chief Executive Officer (CEO), também denominado Diretor executivo ou alta administração, e o programa de GC não é diferente (AKHAVAN; JAFARI; FATHIAN, 2006). O compromisso da alta administração contribui efetivamente como um sustentáculo que subsidia a proposta da GC (WONG, 2005b).

Sedighi e Zand (2012) enfatizam que o apoio da alta administração é fundamental e causa de falhas de projetos de GC. O compromisso dos gerentes e apoio nas fases de implementação de projetos de GC é imperativo para o estabelecimento de confiança e crédito ao programa, elevando assim a sensação dos funcionários de que os intentos almejados são efetivamente apoiados pela alta gestão e passíveis de serem alcançados.

$\mathrm{O}$ apoio advindo dos líderes e gerentes, pode ser financeiro, de direcionar $\mathrm{O}$ conhecimento necessário, de moral e de tempo. A GC demanda financiamento, recursos de infraestrutura e apontamentos quanto aos tipos de conhecimentos mais importantes para a empresa (DAVENPORT; DE LONG; BEERS, 1998), assinalando os campos de conhecimento a serem geridos (TERRA, 2005b). O apoio moral junto a GC tende a promover uma cultura favorável à sua condução (AL-MABROUK, 2006).

Para consecução das atividades orientadas ao conhecimento, a alta administração deve conceder tempo aos líderes no apoio aos demais funcionários nos processos voltados

Perspectivas em Gestão \& Conhecimento, João Pessoa, v. 9, n. 2, p. 174-202, maio/ago. 2019. 
para o conhecimento (KUMAR; SINGH; HALEEM, 2015) bem como os líderes devem prover tempo aos funcionários para aquisição de novos conhecimentos (ARIF; SHALHOUB, 2014). Em suma, os líderes são indivíduos que podem influenciar o comportamento dos demais indivíduos da organização no que tange o compartilhamento do conhecimento, interesse em aprender continuamente e busca por novos conhecimentos.

Os principais gerentes e líderes devem fomentar uma cultura coorporativa que enfatize a cooperação, coordenação e compartilhamento de conhecimento em prol da construção de um ambiente benigno para a criação do conhecimento e aprendizagem. Assim, para que a GC seja implementada é necessário apoio dos líderes, gerentes e suporte da alta administração.

O estudo de Abbaszadeh, Ebrahimi e Fotouhi (2010) elucida que o compromisso e apoio da alta administração, ou sua ausência, tende a influenciar outros Fatores Críticos de Sucesso e, conforme Arif e Shalhoub (2014) a alta administração tende a promover o vínculo da GC aos objetivos estratégicos organizacionais.

Ademais, a liderança e suporte da alta administração foi percebido como o fator de maior importância, haja vista que decisões como a inicialização de um projeto de GC compete a tal administração. Segundo Wong e Aspinwall (2005) e Naghavi, Dastaviz e Nezakati (2013) a escolha de um líder é vista como o primeiro passo em uma iniciativa de GC. Destarte, sem uma liderança capaz e suporte da alta administração a GC pode não ser conduzida com sucesso (KUMAR; SINGH; HALEEM, 2015).

\subsection{Equipe de gestão do conhecimento}

Nas organizações, os profissionais já contratados atendem a determinado perfil para um cargo específico, por vezes técnico, gerencial ou operacional, mas aderentes a alguma ocupação previamente estabelecida perante as necessidades da organização. Quando a perspectiva se altera de funções gerenciais, técnicas ou operacionais para tratativas orientadas ao conhecimento é de suma importância determinar uma estrutura e suas responsabilidades impulsionadas ao conhecimento (AL-MABROUK, 2006; JUNIOR; POLIEZEL; SILVA, 2012).

Uma estrutura de GC significa estabelecer uma equipe de profissionais voltados para a promoção do conhecimento organizacional (DAVENPORT; DE LONG; BEERS, 1998) com papéis específicos (WONG; ASPINWALL, 2005; VALMOHAMMADI, 2010) e responsabilidades (ARIF; SHALHOUB, 2014) como estabelecer processos de conhecimento (LIN; LIN, 2006), coordenar, gerenciar (GAl; XU, 2009) e definir o rumo a ser alcançado pela proposta de GC (WONG, 2005b).

Por coordenar se tem o arranjo dos processos de GC de forma a promover uma cadencia de sua condução no tempo, sendo necessário para orquestrar as pessoas envolvidas e suas habilidades, bem como recursos financeiros, físicos e tratativas relacionadas a sistema de incentivo, plano de comunicação e treinamento (SEDIGHI; ZAND, 2012). Em suma, admite a estruturação e formalização da GC na instituição.

Todo esse processo envolve custo por atribuir novos papéis como chefes do conhecimento, editores, dentre outros (DAVENPORT; DE LONG; BEERS, 1998). Embora exista investimento para tal estrutura, em detrimento das atividades inerentes a essa equipe, esse investimento se torna plausível devido as atividades anteriormente mencionadas.

Ademais, uma vez que a GC necessita de alinhamento estratégico com os objetivos organizacionais e tratativas relacionadas a outras interfaces, como melhoria da cultura com vistas ao compartilhamento e treinamento em tecnologias criadas com foco no conhecimento, uma equipe que assuma responsabilidades por tais tratativas é admissível de ser considerada (DAVENPORT; DE LONG; BEERS, 1998).

Perspectivas em Gestão \& Conhecimento, João Pessoa, v. 9, n. 2, p. 174-202, maio/ago. 2019. 
Embora seja imperativo o estabelecimento de uma equipe de GC, o custo inerente aos novos profissionais pode ser elevado para algumas organizações. A análise de Wong (2005b) demonstra que grandes empresas podem ter recursos elevados, mas no tocante de pequenas e médias empresas a equipe de GC pode adotar uma menor configuração devido a disponibilidade financeira.

Assim, definir papéis dentre os quais, o de chefe de conhecimento ou gestor do conhecimento, resulta no estabelecimento de uma equipe de GC responsável pela condução, coordenação, gerenciamento e estabelecimento de processos de conhecimento rumo ao que se pretende alcançar pela proposta de GC.

\subsection{Recursos (financeiro, humano, material e tempo)}

Recursos são necessários em qualquer iniciativa organizacional. Embora a GC atue com foco em um ativo intangível - o conhecimento - sua operacionalização demanda insumos tangíveis e também intangíveis como recursos financeiros, humanos, materiais e de tempo (WONG; ASPINWALL, 2005; AL-MABROUK, 2006; GAI; XU, 2009; ABBASZADEH; EBRAHIMI; FOTOUHI, 2010; JUNIOR; POLIEZEL; SILVA, 2012).

O aporte financeiro é necessário uma vez que a GC pode demandar sistemas tecnológicos específicos (AL-MABROUK, 2006; ABBASZADEH; EBRAHIMI; FOTOUHI, 2010) havendo a necessidade de sua aquisição ou desenvolvimento. Ademais, outros recursos são derivados desses como pessoas e materiais.

As pessoas, que caracterizam a equipe de GC, são indispensáveis para operacionalizar todas as tratativas que consideram o conhecimento (WONG, 2005b; LIN; LIN, 2006; GAl; XU, 2009). Portanto, a organização deve conceder recursos humanos para a condução da GC (WONG, 2005b) e, como tal, estes acarretam em investimentos financeiros oriundos dos salários dos colaboradores.

Assumida uma equipe de $\mathrm{GC}$, a necessidade de um local para sua instalação é vital (KUMAR; SINGH; HALEEM, 2015). Equipamentos materiais, como computadores e outros artigos físicos e infraestrutura, devem ser fornecidos para a execução do trabalho das pessoas que conduzem a GC na organização (SEDIGHI; ZAND, 2012). O tempo deve ser contemplado quando a GC é implementada. As organizações devem conceder tempo para que seus funcionários executem atividades de GC como compartilhamento de conhecimento (ALMABROUK, 2006) e para que os membros responsáveis pela GC possam executar os processos planejados.

Uma vez que a disponibilidade de recursos é uma preocupação primordial nas organizações, essa deve ser considerada quando se adota uma iniciativa de GC (LIN, LIN, 2006). Estes insumos assumem relação direta com a alta administração, uma vez que, essa deve alocar e designar tais insumos para a realização efetiva da GC (VALMOHAMMADI, 2010). No estudo de Kumar, Singh e Haleem (2015) os recursos, infraestrutura e instalações são percebidos como o segundo fator de maior importância para a GC por serem insumos que permitirão sua fundamentação real em solo organizacional e, portanto, são indiscutivelmente necessários.

A avaliação de disponibilidade dos diversos recursos e sua concessão podem ser ações desempenhadas pela alta administração em conjunto com outros setores organizacionais competentes, como projetos e recursos humanos. Demais ações como a disponibilização de infraestrutura física e de tempo para dedicação ao compartilhamento do conhecimento são processos que, possivelmente, podem ser delegados, ou compartilhados, com outros setores organizacionais.

Perspectivas em Gestão \& Conhecimento, João Pessoa, v. 9, n. 2, p. 174-202, maio/ago. 2019. 


\subsection{Processos e atividades}

Os processos e atividades são o centro da GC por serem manuseadores do conhecimento e estão relacionados ao ciclo de vida desse ativo. Tais processos elucidam o que pode ser feito com o conhecimento (WONG, 2005a; ABBASZADEH; EBRAHIMI; FOTOUHI, 2010) e são o núcleo da criação de uma empresa voltada para o conhecimento (SEDIGUI; ZAND, 2012).

Alguns como identificação, armazenamento, compartilhamento e criação do conhecimento refletem o intento da GC voltado para tal manuseio (WONG, 2005b) e são adotados em diversos modelos de GC, cada qual com determinada característica e, comumente, não lineares (VALMOHAMMADI, 2010; SEDIGHI; ZAND, 2012). Diante do foco sobre o conhecimento, tais processos resultam em atividades que visam identificar e armazenar o conhecimento relevante para organização, ou informações sobre seu conhecedor, de forma a permitir localizá-lo e acessá-lo, seja em meios digitais ou pelo contato entre pessoas (SKYRME; AMIDON, 1997).

Uma vez armazenado, o compartilhamento do conhecimento se torna primordial e pode ser realizado regularmente (reuniões diárias) ou eventualmente (eventos especiais como o fechamento de um projeto), mantendo uma memória organizacional e ampliando a possibilidade de acesso a esse conhecimento aos demais indivíduos da empresa (AKHAVAN; JAFARI; FATHIAN, 2006).

Valmohammadi (2010) cita o processo cíclico de criação do conhecimento proposto por Nonaka e Takeuchi (1997). Esse processo, centrado na criação do novo conhecimento organizacional, alude cinco fases (processos) sendo: compartilhamento do conhecimento tácito, criação de conceitos, justificação de conceitos, construção de um arquétipo e difusão interativa do conhecimento.

Dessa forma é necessário compreender os fluxos dos processos relacionados a GC para sua condução, operacionalização (VALMOHAMMADI, 2010) e coordenação (AL-MABROUK, 2006), devendo esses serem integrados ao fluxo de trabalho de forma clara para que os indivíduos possam desempenhá-los de forma estruturada e sistemática (GAl; XU, 2009). Consequentemente, uma vez integrados aos fluxos diários dos funcionários estes tendem a acarretar em mudanças nas atividades e comportamento nos indivíduos (ABBASZADEH; EBRAHIMI; FOTOUHI, 2010).

Portanto, mediante a alguns dos processos relacionados acima e perante sua importância para a GC, estes são considerados Fatores Críticos de Sucesso (WONG; ASPINWALL, 2005) e carecem de orquestração em sua condução. Os processos e atividades orientados ao conhecimento devem ser estabelecidos e integrados aos processos de trabalho dos indivíduos para que a GC possa ser intensificada e praticada nas organizações que se inclinam para a promoção do conhecimento.

\subsection{Gestão de recursos humanos}

A gestão de recursos humanos (GRH) é imperativa para tratativas relacionadas ao conhecimento, pois as pessoas são a pedra angular da GC uma vez que o conhecimento advém de suas mentes (VALMOHAMMADI, 2010) o que os caracteriza como detentores do conhecimento e elementos chave para a GC (SEDIGHI; ZAND, 2012).

Sob esta perspectiva, os processos de recrutamento, desenvolvimento e retenção de funcionários, desempenhados pela GRH, são vitais para o sucesso da GC (ABBASZADEH; EBRAHIMI; FOTOUHI, 2010) por municiar a empresa de colaboradores possuidores de conhecimentos relevantes ao propósito organizacional.

Perspectivas em Gestão \& Conhecimento, João Pessoa, v. 9, n. 2, p. 174-202, maio/ago. 2019. 
De forma ampla, o recrutamento deve considerar a captação de pessoas que possam preencher lacunas de conhecimentos identificadas na organização (WONG; ASPINWALL, 2005) e tais indivíduos devem ser aderentes a cultura almejada pela GC, com perfil colaborativo e que promovam a partilha de seus saberes (WONG, 2005b).

Por outra perspectiva, o desenvolvimento considera a capacitação dos indivíduos, por meio de habilidades e competências, para aplicação posterior na empresa e atingimento dos intentos almejados (WONG, 2005b; KUMAR; SINGH; HALEEM, 2015).

Por conseguinte, a retenção consiste em formas de manter o indivíduo na organização, sendo políticas de carreira uma ação a ser considerada para que os anseios dos colaboradores sejam passíveis de serem alcançados, acarretando no desejo de se manterem na organização e na satisfação pessoal em detrimento ao trabalho desempenhado (WONG, 2005b).

Portanto, a GRH se concentra nos processos acima relacionados, dentre outros, que consequentemente resultarão no comportamento de compartilhamento do conhecimento levando futuramente a uma cultura organizacional adequada a GC. Assim, a GRH é um fator que influencia em diversos aspectos organizacionais por atuar no cerne do conhecimento: as pessoas (ANGGIA et al., 2013).

Wong (2005b), Al-Mabrouk (2006) e Valmohammadi (2010) conferem crédito a afirmação de Davenport e Völpel (2001, p. 218, tradução dos autores) de que "[...] gerenciar conhecimento é gerenciar pessoas; gerenciar pessoas é gerenciar conhecimento". É importante ressaltar que interpretações a esta afirmação podem resultar na percepção de que a GC deve gerir os indivíduos da organização, o que representaria uma leitura incoerente.

A GRH resulta na gestão das pessoas da organização e gerenciá-las é preponderante para GC, uma vez que tais perfis podem incentivar a criação e compartilhamento do conhecimento (SEDIGHI; ZAND, 2012), fatores estes almejados e diretamente relacionados ao intento da GC. No entanto, as pessoas são incumbência da GRH. Contrapondo a colocação de Davenport e Völpel (2001), Teixeira Filho (2000, p. 12) afirma que a GC "[...] não é gestão de recursos humanos, mas só se realiza com as pessoas da organização".

$\mathrm{O}$ conhecimento, derivado das mentes desses indivíduos é o elemento norteador da GC, que tem por foco sua avaliação para melhoria continua (KUMAR; SINGH; HALEEM, 2015). Assim, a GC se fundamenta no conhecimento que advém dos indivíduos e não nos indivíduos em si. O limiar que distingue os elementos conhecimento e o conhecedor é sútil, mas quando delimitado firmemente resulta na determinação de responsabilidade de cada um desses elementos aos seus devidos setores.

Assim, no que tange as menções de Wong (2005b), Al-Mabrouk (2006) e Valmohammadi (2010) quanto a colocação de Davenport e Völpel (2001), esse estudo assinala, visando uma correta compreensão quanto a gestão, que as pessoas são encargo da GRH e o conhecimento das pessoas é de foco e responsabilidade da GC que, ademais, tal distinção está diretamente relacionada a terminologia que rotula a GC e GRH.

\subsection{Treinamento e educação}

O vocabulário da GC se dissocia dos demais vocabulários por assumir distinção entre dados, informação e conhecimento. Definir claramente o que são estes termos no contexto da GC tende a evitar interpretações subjetivas. O exemplo de um gerente de conhecimento ressalta esta relevância, ao afirmar que:

A linguagem de negócios normal dá a impressão de ser baseada em fato, muitas vezes com base em metáforas de ciência militar e natural. Mas o gerenciamento do conhecimento lida com coisas como complexidade, incerteza e crescimento orgânico. Isso exige um novo vocabulário, e os

Perspectivas em Gestão \& Conhecimento, João Pessoa, v. 9, n. 2, p. 174-202, maio/ago. 2019. 
gerentes não estão acostumados a isso. A linguagem é mais provável, convida ao debate e expõe a incerteza que todos nós temos (DAVENPORT; DE LONG; BEERS, 1998, p. 53, tradução dos autores).

Uma linguagem clara quanto ao vocabulário e propósito da GC tende a ser aceita de forma mais coesa ao intento da GC. Assim, os gerentes de GC devem ser claros quanto aos objetivos almejados pelo projeto que gerenciam (DAVENPORT; DE LONG; BEERS, 1998).

Na perspectiva dos funcionários, estes devem ser treinados para compreender a GC e utilizar as ferramentas voltadas para o conhecimento, promovendo a elevação de uma conscientização que permita entender as responsabilidades e suas contribuições para com a GC (GAI; XU, 2009), a relevância do compartilhamento do conhecimento (VALMOHAMMADI, 2010), do comportamento colaborativo e em equipe (SKYRME; AMIDON, 1997; WONG, 2005b).

Neste âmbito, o treinamento de gerentes e funcionários é relevante para compreensão da linguagem da GC e tende a homogeneizar conceitos (AL-MABROUK, 2006; AKHAVAN; JAFARI; FATHIAN, 2006), vocábulo, mensagem, papéis a serem desempenhados pela equipe de GC (WONG, 2005b), seu propósito (DAVENPORT; DE LONG; BEERS, 1998), bem como municiar os indivíduos de habilidades para desenvolver suas atividades (ANGGIA et al., 2013) e manusear as ferramentas voltadas para o conhecimento (ABBASZADEH; EBRAHIMI; FOTOUHI, 2010), preparando um campo fértil para que os funcionários participem efetivamente do programa de GC (SEDIGHI; ZAND, 2012).

Outro aspecto relevante é elucidar aos membros da organização que o aprendizado também é decorrente dos acertos e falhas em todos os níveis, entre equipes e de forma compartilhada e contínua (SKYRME; AMIDON, 1997; ARIF; SHALHOUB, 2014) sendo que a organização deve ser flexível na admissão de erros.

Por benefícios, o treinamento pode conduzir a melhora da atitude, habilidade e conhecimento por meio do aprendizado que tende a promover uma melhoria no desempenho das atividades realizadas pelo indivíduo e da organização como um todo. A educação, provida por meio do treinamento, tende a ser benéfica para veteranos ou recém-admitidos não somente em suas atividades, mas também de forma a fomentar a criatividade para um possível surgimento de ideias inovadoras (KUMAR; SINGH; HALEEM, 2015).

A relevância do treinamento e da educação está em municiar profissionais de conhecimentos que possam ser úteis em suas atividades, conduzindo a uma melhor equipe de trabalho organizacional. No que tange novas contratações, assume relevo por orientar os novos profissionais quanto a cultura e processos organizacionais que permitem melhor engajamento do indivíduo na organização (KUMAR; SINGH; HALEEM, 2015).

$\mathrm{O}$ treinamento admite diversos aspectos, desde o desenvolvimento de habilidades individuais e em grupo e adequação terminológica ao vocábulo da GC até o esclarecimento dos intentos da proposta orientada ao conhecimento e apresentação da importância do indivíduo no programa, acarretando na importância desse fator para a GC.

\subsection{Motivação}

Os incentivos são meios utilizados para motivar os indivíduos a compartilharem o que sabem em prol de uma prática colaborativa, sendo relevante sua projeção a longo prazo para apoiar o sistema de avaliação de desempenho dos funcionários (WONG, 2005b; SEDIGHI; ZAND, 2012). Consiste no estabelecimento de formas de recompensas para que os funcionários se envolvam e pratiquem a GC (TERRA, 2005a; AL-MABROUK, 2006; LIN; LIN, 2006).

Perspectivas em Gestão \& Conhecimento, João Pessoa, v. 9, n. 2, p. 174-202, maio/ago. 2019. 
Encontrar formas de motivar a criação, partilha e uso do conhecimento é um desafio para a GC (DAVENPORT; DE LONG; BEERS, 1998). No entanto, deve-se considerar que tais incentivos não necessariamente estão relacionados a retornos financeiros, podendo ser por meio de recompensas (VALMOHAMMADI, 2010), reconhecimento (TERRA, 2005a; WONG; ASPINWALL, 2005; JUNIOR; POLIZEL; SILVA, 2012) e valoração do indivíduo (ZIEBA; ZIEBA, 2014).

Algumas práticas motivacionais por recompensas foram registradas por Davenport, De Long e Beers (1998) como milhas de passagens para indivíduos que contribuíssem ou navegassem em bancos de dados de discussão e délicatesses ou artigos tecnológicos para especialistas que biografassem um sistema, sendo estas ações de curto prazo; enquanto o reconhecimento pode ser visto pelo exemplo da Buckman Laboratories, que reconhece as pessoas que contribuem e compartilham boas ideias.

Para Zieba e Zieba (2014), a valoração do funcionário pode ser contemplada ao considerar o que estes indivíduos conhecem e pelo oferecimento de oportunidade de carreira. Assim, o intento é incentivar ações voltadas ao compartilhamento do conhecimento, o que tende a criar um clima propício para a GC (ZIEBA; ZIEBA, 2014).

Em tempo, ressalta-se o resultado do estudo de Wong e Aspinwall (2005), no qual os incentivos motivacionais ao compartilhamento do conhecimento podem não apresentar relevância em primeiro momento, podendo tais incentivos serem considerados após contemplar outros Fatores Críticos de Sucesso da GC.

O elo que conecta os incentivos motivacionais às necessidades da GC está relacionado ao que se almeja das pessoas no que tange o conhecimento. Além do compartilhamento, a contribuição, colaboração, criatividade e trabalho em equipe são critérios ambicionados pela GC (GAl; XU, 2009) e podem ser motivados por meio destas práticas.

Os indivíduos devem estar motivados para que a GC aconteça, e incentivar os funcionários tende a estimular o comportamento dos mesmos em relação ao objetivo da GC e seus processos (WONG; 2005b). Nenhum investimento destinado a GC, alocação de recursos humanos ou de tempo serão suficientemente eficazes se as pessoas não estiverem motivadas para contribuir com os processos relacionados ao conhecimento (AL-MABROUK, 2006; VALMOHAMMADI, 2010).

Em suma, na perspectiva de Arif e Shalhoub (2014), motivar alude criar um sistema de incentivo à partilha de conhecimento e a melhoria de desempenho pelo conhecimento. Outras ações apresentadas pelos pesquisadores quanto a motivação demanda atuações que se enquadram nos processos de $\mathrm{RH}$ como i) recrutar profissionais comprometidos com a criação e o compartilhamento do conhecimento; ii) desenvolvimento e manutenibilidade dos funcionários; iii) preenchimento da lacuna de conhecimento existente.

Embora a GC deva considerar a necessidade de contemplar formas motivacionais relacionadas ao seu intento, algumas, como plano de carreira e recompensas, dentre outras supracitadas, perpassam pela GRH. Nesse aspecto a GC pode sinalizar a GRH práticas motivacionais que, no entanto, devem ser desenvolvidas pela estrutura de recursos humanos.

\subsection{Trabalho em equipe}

Uma equipe pode ser compreendida como a reunião de dois ou mais indivíduos que se influenciam e interagem (WAI; HONG; DIN, 2011). Estar em equipe tende a cooperação entre as pessoas e elevação do potencial de processos e atividades da GC (SEDIGHI; ZAND, 2012). Logo, as equipes de trabalho são meios férteis para a criação e compartilhamento do conhecimento (WAl; HONG; DIN, 2011).

A GC não erradica o trabalho individual, pois esse é necessário em detrimento a algumas atividades e funções que possam demandar alocação de um único indivíduo; no

Perspectivas em Gestão \& Conhecimento, João Pessoa, v. 9, n. 2, p. 174-202, maio/ago. 2019. 
entanto percebe os frutos a serem colhidos por meio da comunhão entre indivíduos em equipe, voltados para o atingimento de um objetivo comum (SEDIGHI; ZAND, 2012).

Além do objetivo em comum (PESTANA et al., 2002; SEDIGHI; ZAND, 2012), aspectos positivos relacionados as equipes de trabalho podem ser elencadas como o estabelecimento de relações pessoais abertas e de amizade, liderança da equipe baseada na competência e membros que opinam sobre a constituição da equipe (TERRA, 2005a) que tendem a fomentar um círculo colaborativo.

Terra (2005a) sinalizava alguns desafios da GC, dentre os quais "[...] como manter o equilíbrio entre o trabalho em equipe e o trabalho individual" (TERRA, 2005a, p. 4). O balanceamento destas formas de labor é uma consideração da GC, ao perceber que "[...] a ênfase dada no trabalho em equipe passa a ser o conhecimento trabalhado, e não o trabalho do conhecimento" (REZENDE, 2002).

Portanto, a troca de conhecimento promove o desenvolvimento do conhecimento organizacional (AKHAVAN; JAFARI; FATHIAN, 2006) e as equipes, constituídas por indivíduos possuidores de habilidades diferentes, tendem a ampliar a perspectiva de troca de conhecimento para criação desse ativo (WAl; HONG; DIN, 2011) sendo esse um dos propósitos da GC.

\subsection{Cultura}

A cultura consiste em parâmetros de valores, normas e costumes sociais que moldam a forma como as pessoas se comportam (FLEURY, 1996; MINTZBERG et al., 2000; ALMABROUK, 2006; BURMESTER, 2012; JUNIOR; POLIZEL; SILVA, 2012). Assim, uma cultura propícia a GC deve fomentar a partilha do conhecimento, admissão de erros e reconhecimento do potencial de aprendizado por meio desses, dentre outros aspectos que regem uma atmosfera voltada ao conhecimento (WONG, 2005b).

Consiste no estabelecimento de um alto grau de confiança mutua entre os funcionários (GAI; XU, 2009; VALMOHAMMADI, 2010) no qual emerge um forte link entre os indivíduos para o estabelecimento de um ambiente colaborativo (LIN; LIN, 2006) que tende a valorizar o conhecimento, sua criação, compartilhamento e aplicação no âmbito organizacional (AL-MABROUK, 2006).

Para que a GC obtenha uma cultura fértil orientada ao conhecimento são necessárias mudanças comportamentais, haja visto que muitos de seus processos assumem características voluntárias e dependem das pessoas acarretando na necessidade de um sentimento de pertencimento do indivíduo à organização e à GC (WONG; ASPINWALL, 2005; AKHAVAN; JAFARI; FATHIAN, 2006).

Uma cultura amigável ao conhecimento resulta em um ambiente no qual os funcionários sintam-se confortáveis em compartilharem o que sabem, sem que isto lhes custe suas funções. Funcionários que percebem um ambiente propício para compartilharem o que sabem e criarem novos conhecimentos, sem retaliações, fomentam uma cultura fecunda à GC (DAVENPORT; DE LONG; BEERS, 1998). Alguns motivos que situam a necessidade de uma cultura orientada a GC são salientados por Davenport, De Long e Beers (1998), ao sinalizarem circunstâncias que levam a um funcionário a não compartilhar seus conhecimentos, as quais conflitam diretamente com o intento da GC.

Os erros decorrentes de tentativas de acertos são fontes de aprendizagem louváveis, mas muitos funcionários não os divulgam com receio de serem demitidos. Em outros casos, os funcionários não compartilham seus conhecimentos com receio de que sejam dispensados posteriormente a divulgação de seus saberes. Ambos motivos são percebidos pelos pesquisadores em uma empresa de engenharia e podem ser resquícios do downsizing aplicado em empresas dos Estados Unidos (DAVENPORT; DE LONG; BEERS, 1998).

Perspectivas em Gestão \& Conhecimento, João Pessoa, v. 9, n. 2, p. 174-202, maio/ago. 2019. 
Outro aspecto cultural é exposto por meio do exemplo da Hewlett Packard (HP) que promovia iniciativas de GC descentralizadas em detrimento a autonomia das unidades de negócios e, segundo os executivos da HP, um projeto coordenado poderia não ser suportado pela empresa. Esse aspecto evidencia que "projetos que não se encaixam na cultura provavelmente não prosperarão, então a gerência precisa alinhar sua abordagem com sua cultura existente - ou estar preparado para um esforço de mudança de cultura a longo prazo" (DAVENPORT; DE LONG; BEERS, 1998, p. 53, tradução dos autores).

Considerando toda a complexidade existente na GC, uma mudança cultural resultaria um esforço expressivo, e conforme supracitado, uma mudança dessa magnitude seria de longo prazo. Para Bukowitz e Williams (2002, p. 291) "[...] essa mudança leva de 5 a 10 anos", enquanto para Miller (2002, apud MENDES, 2006, p. 148) "[...] pode levar de 3 a 7 anos". A intangibilidade desse Fator Crítico de Sucesso demarca a dificuldade inerente a possibilidade de mudança, porém, se a cultura organizacional não for favorável a GC deve-se considerar sua mutação no que se refere a GC.

Destarte, a GC demanda aspectos intangíveis relacionados às crenças, valores e normas dos indivíduos que, no ambiente organizacional, acarretam em uma cultura que formata o modo de ser dos indivíduos perante a organização e, caso a percepção dos indivíduos seja negativa, há de se considerar mudanças nestes aspectos para 0 estabelecimento de uma atmosfera amigável ao conhecimento.

\subsection{Tecnologia da informação}

A Tecnologia da Informação (TI) é um facilitador eficaz de manipulação (captura, armazenamento e divulgação) do conhecimento (AL-MABROUK, 2006) e sua relevância para a GC é indiscutível (WONG, 2005b); no entanto é imperativo frisar que essa deve ser percebida como um meio para os processos da GC e não como uma solução definitiva (ABBASZADEH; EBRAHIMI; FOTOUHI, 2010; VALMOHAMMADI, 2010).

As menções a $\mathrm{Tl}$ em relação a GC podem ser divididas pela perspectiva da tipologia de conhecimento a ser gerida. Assumindo a tipologia de conhecimento tácito e explícito, a TI deve ser compreendida não somente pela perspectiva técnica voltada para o conhecimento explícito, mas também como um meio potencial para conectar as pessoas em prol do conhecimento tácito (GAI, XU, 2009).

Por meio de tecnologias como videoconferência e telefones o conhecimento tácito pode ser compartilhado entre indivíduos e a TI atua como elemento de conexão entre as pessoas (SKYRME; AMIDON, 1997; WONG; ASPINWALL, 2005; JUNIOR; POLIZEL; SILVA, 2012; SEDIGHI; ZAND, 2012; KUMAR; SINGH; HALEEM, 2015).

Pelo aspecto técnico, a Tl é um meio pelo qual o conhecimento explícito tende a ser armazenado (WONG; ASPINWALL, 2005) e compartilhado na organização (ANGGIA et al., 2013), pelo uso de banco de dados, intranet (SEDIGHI; ZAND, 2012) e internet (KUMAR; SINGH; HALEEM, 2015).

Diversos estudos exploram a perspectiva técnica quanto a organização do conhecimento explícito em repositórios (KUMAR; SINGH; HALEEM, 2015) de forma que esses possam ser disseminados na empresa e recuperados por meio do uso de palavras-chave, dicionários de sinônimos e tesauros, fazendo uso de outros artifícios de indexação como a taxonomia (DAVENPORT; DE LONG; BEERS, 1998; ARIF; SHALHOUB, 2014).

Por conseguinte, para Davenport, De Long e Beers (1998) há necessidade de que a TI seja flexível para admitir novos conhecimentos ainda não previstos para sua correta inclusão no repositório, permitindo assim que o conhecimento seja armazenado assertivamente ao longo do tempo.

Perspectivas em Gestão \& Conhecimento, João Pessoa, v. 9, n. 2, p. 174-202, maio/ago. 2019. 
No seguimento de saúde o estudo de Wong e Aspinwall (2005) aferiu que os médicos não percebem a $\mathrm{TI}$ como fator relevante para a GC, uma vez que assumem formas convencionais de compartilhamento do conhecimento médico. A percepção dos entrevistados no estudo de Wong e Aspinwall (2005) demarca e enfatiza o papel da TI como mediador na GC.

Não somente na GC, mas em diversos segmentos, a TI é um meio que amplia as capacidades e operações das empresas por meio da automação e padronização de processos, dentre outras possibilidades. Devido a isso, sua relevância demarca forte relação junto a GC.

\subsection{Mensuração}

Medir a GC é necessário para que seja possível identificar se os objetivos foram alcançados e avaliar o seu progresso para a promoção de melhoria continua do programa em prol do aperfeiçoamento do desempenho estabelecido para a GC (VALMOHAMMADI, 2010; KUMAR; SINGH; HALEEM, 2015). Resulta em determinar metas mensuráveis para posterior medição (LIN, LIN, 2006).

Uma vez mensurado, ações comparativas com outras empresas permitem que a organização se posicione diante de um parâmetro para se avaliar perante a seus concorrentes e parceiros de forma a evoluir em suas iniciativas de GC (VALMOHAMMADI, 2010) permitindo a melhoria dos processos voltados ao conhecimento (TERRA, 2005a; BUKOWITZ; WILLIAMS, 2002).

A medição também visa criar formas de conectar os esforços da GC versus o desempenho econômico, refletindo no esforço de avaliar o desempenho organizacional sob diversas óticas (TERRA, 2005a), sendo comum indicadores e métricas financeiras e aceitáveis medições não financeiras (GAl; XU, 2009) devido a intangibilidade do conhecimento. Esforços contundentes nesta área são empregados pelo campo de estudo denominado capital intelectual (AL-MABROUK, 2006; SEDIGHI; ZAND, 2012).

Diante da dificuldade de relacionar GC e desempenho econômico, seus benefícios podem ser identificados por meio de valor economizado e obtido como na Dow Chemical, que economizou US\$ 4 milhões no primeiro ano com impostos de patentes não mais úteis e Hoffmann-LaRoche, que economizou tempo na aprovação de novos medicamentos nos quais, a cada dia passado no processo de aprovação US\$ 1 milhão em receitas eram perdidas (DAVENPORT; DE LONG; BEERS, 1998).

Davenport, De Long e Beers (1998) aludem que talvez identificar os benefícios pela GC, como nos casos das empresas anteriores, seja mais factível de ser feito do que medir o intangível. Aferir os benefícios ao invés de tentar medi-los pode ser mais útil para melhorar a percepção dos investidores que visam perceber os retornos de um projeto de GC e, portanto, tendem a receber suporte quando relacionado, de alguma forma, com benefícios econômicos ou à vantagem competitiva.

Outra forma de mensuração é empregada pelas auditorias e tendem a medir a GC em diversas faces e identificar lacunas a serem sanadas (AKHAVAN; JAFARI; FATHIAN, 2006), podendo fazer uso de diagnósticos como proposto por Angeloni (2002), Bukowitz e Williams (2002), Terra (2005a), APO (2009), Fonseca (2006) e Batista (2012).

Assim a medição é necessária para que seja possível mensurar o quanto do almejado foi atingido. Isto resulta em expressar o mérito e sucesso, ou falha, da investida para as partes interessadas (TERRA, 2005a; AL-MABROUK, 2006) e municiar a alta administração de informações que fomente seu apoio continuo (WONG, 2005b).

O estudo de Wong e Aspinwall (2005) apontou a medição como fator menos importante no contexto das pequenas e médias empresas, possivelmente por demandar que a GC esteja em operação para sua posterior aferição e melhoria. Por outra perspectiva o estudo de Kumar, Singh e Haleem (2015) apontou esse fator como o terceiro mais importante no

Perspectivas em Gestão \& Conhecimento, João Pessoa, v. 9, n. 2, p. 174-202, maio/ago. 2019. 
âmbito industrial, podendo ser útil em apoiar a implementação de treinamento mediante a avaliação realizada.

Para Arif e Shalhoub (2014) a medição deve considerar algumas perspectivas como: i) avaliação da GC, considerando a liderança, coordenação e controle; i) sistema de controle de qualidade para compartilhamento do conhecimento; iii) benchmark de simulação com outras instituições; iv) medida que destaque a importância da GC e suas vantagens para a organização; v) medida entre atividades, valor agregado e impacto na produtividade; e vi) instruções para criação de referência padrão ao campo de GC.

Assim, a mensuração considera o estabelecimento de indicadores para medição e formas alternativas de aferição dos benefícios da GC, sendo relevante para verificar os ganhos da GC durante sua condução e diagnóstico das diversas dimensões antes de sua implementação.

\subsection{Projeto piloto}

Antes de promover uma implantação da GC em toda a organização um projeto piloto pode ser considerado visando identificar melhores práticas de forma a aumentar o potencial de acerto por meio de lições aprendidas (SKYRME; AMIDON, 1997; AKHAVAN; JAFARI; FATHIAN, 2006).

As investidas promovidas pela Microsoft, Hewlett-Packard e BP Exploration (segmento petrolífero), segundo Akhavan, Jafari e Fathian (2006), se valeram de programas piloto que, após o aprendizado obtido pela sua aplicação em menor escala, foi possível expandir o programa ao âmbito organizacional (AKHAVAN; JAFARI; FATHIAN, 2006).

No Brasil, o estudo de Futami (2001) apresenta um modelo de trabalho em rede que "[...] focaliza a produção do conhecimento e insere um mecanismo concreto para transformar o conhecimento tácito das pessoas em conhecimento explícito" (FUTAMI, 2001, p. 146). A proposta foi implementada em uma unidade de sistema de refrigeração de uma organização fabricante de bens de consumo eletroeletrônicos, evidenciando a empiricidade de programas pilotos de GC em solo brasileiro.

Skyrme e Amidon (1997) salientam que para projetos pilotos nem todos os fatores, discorridos neste estudo, são relevantes; no entanto estes se repetem nas organizações. Os autores ainda sinalizam que a área de negócios é um ponto contemplado em diversas organizações para implementação de projetos pilotos por ser mais factível de vislumbrar os benefícios da GC.

Assim, programas pilotos tendem a municiar de experiências os membros que conduzem a GC e prepará-los para situações que poderão ocorrer em uma aplicação de maior amplitude. Ademais, Skyrme e Amidon (1997) já sinalizavam que, na época de seu estudo, poucas organizações aplicavam a GC em toda a organização, sendo prática comum adotar projetos pilotos.

Considerando que em 1997 a GC ainda era um campo consideravelmente recente (BOLISANI; HANDZIC, 2015) e embora possam haver iniciativas que contemplem a totalidade organizacional desde o início de um projeto de conhecimento, um projeto piloto ainda pode ser relevante pela combinação de outros fatores como recursos e apoio da alta administração, que podem ser elevados pelos benefícios identificados por uma primeira iniciativa em menor escala.

Diante da complexidade existente para operacionalização de cada Fatores Críticos de Sucesso e perante a elevação desta complexidade em detrimento da interação entre estes fatores, admitir um projeto piloto pode ser relevante como uma forma de experimentação de como a GC pode ser conduzida.

Perspectivas em Gestão \& Conhecimento, João Pessoa, v. 9, n. 2, p. 174-202, maio/ago. 2019. 


\section{CONSIDERAÇÕES FINAIS}

A GC holística ajusta o gerenciamento do conhecimento ao paradigma holístico. Para que se possa gerir o conhecimento de forma holística, torna-se necessário conhecer as partes (dimensões) que constituem o todo (GC), permitindo assim, que tais partes sejam analisadas em conjunto e não mais isoladamente. Desse modo, esta pesquisa objetivou conformar (identificar e consolidar) as dimensões que compõem a GC rumo a uma abordagem holística.

Foi analisado o conteúdo de 18 pesquisas científicas, com traço temporal de 1997 a 2015, de modo a identificar os fatores apresentados nessas como críticos para o êxito da GC. A semântica desses fatores permitiu agrupá-los em 13 dimensões que conformam o gerenciamento do conhecimento amparado nos preceitos do paradigma holístico. Desse modo, segundo os princípios deste paradigma, estes fatores devem ser contemplados conjuntamente em modelos de GC, sendo: 1) Estratégia; 2) Liderança e suporte da alta administração; 3) Equipe de gestão do conhecimento; 4) Recursos (financeiro, humano, material e tempo); 5) Processos e atividades; 6) Gestão de recursos humanos; 7) Treinamento e educação; 8) Motivação; 9) Trabalho em equipe; 10) Cultura; 11) Tecnologia da informação; 12) Mensuração; e 13) Projeto piloto.

Cada uma dessas 13 dimensões foram fundamentadas teoricamente de forma a permitir a compreensão da abrangência das mesmas no âmbito da GC holística. A exemplo, o alinhamento da estratégia da GC à estratégia do negócio - dimensão Estratégia - e sua clarificação aos demais membros da organização é imprescindível para que a GC apoie os objetivos empresariais e para que os empregados ajam rumo ao atingimento dos intentos ambicionados pela GC para a organização.

A conformação dessas dimensões tende a permitir que novos estudos desenvolvam modelos de GC voltados para as mesmas e concernentes ao paradigma holístico. Ressalta-se que para isso tais modelos devam ser orientados a prover análises sobre essas dimensões, considerando suas relações com as demais. Desse modo, a perspectiva holística tende a prover uma forma mais coesa para que o gerenciamento do conhecimento no todo organizacional.

Todavia, a relação entre essas dimensões não foram exploradas, sendo uma limitação dessa pesquisa. No entanto, o presente estudo produz um passo inicial: a delimitação dessas dimensões. A relação entre essas é uma sugestão de pesquisa futura, bem como o desenvolvimento de um modelo que contemple todas as referidas dimensões em uma estrutura que possa, então, ser denominada holística para a GC.

\section{REFERÊNCIAS}

ABBASZADEH, M. A.; EBRAHIMI, M.; FOTOUHI, H. Developing a causal model of critical success factors for knowledge management implementation. ICEMT 2010 - 2010 International Conference on Education and Management Technology, Anais [...]. Proceedings, p. 701-705, 2010. DOI http://dx.doi.org/10.1109/ICEMT.2010.5657563.

AKHAVAN, P.; JAFARI, M.; FATHIAN, M. Critical success factors of knowledge management systems: A multi-case analysis. European Business Review, v.18, n. 2, p. 97-113, 2006. DOI http://dx.doi.org/10.1108/09555340610651820.

AL-MABROUK, K. Critical success factors affecting knowledge management adoption: A review of the literature. Anais... 2006 Innovations in Information Technology, IITFALSO, 2006. DOI http://dx.doi.org/10.1109/INNOVATIONS.2006.301888

Perspectivas em Gestão \& Conhecimento, João Pessoa, v. 9, n. 2, p. 174-202, maio/ago. 2019. 
ALTAHER, A. M. Critical success factors of implementation knowledge management process. Anais [...]. 2010 International Conference on Information Society, i-Society 2010, p. 340-348, 2010.

ANGELONI, M. T. (org.). Organizações do conhecimento: infra-estrutura, pessoas e tecnologia. São Paulo: Saraiva, 2002.

ANGGIA, P. et al. Identifying critical success factors for knowledge management implementation in organization: A survey paper. Anais... 2013 International Conference on Advanced Computer Science and Information Systems, ICACSIS 2013, p. 83-88, 2013. DOI http://dx.doi.org/10.1109/ICACSIS.2013.6761556

APO - ASIAN PRODUCTIVITY ORGANIZATION. Knowledge management: facilitator's guide. 2009. Disponível em: <http://www.apo-tokyo.org/00e-books/IS-39_APO-KM-FG.htm> Acessado em: 09 fev. 2017.

ARIF, M. J.; SHALHOUB, M. H. B. Critical success factors with its effective role in knowledge management initiatives in public and private organizations in saudi Arabia: experts perspectives. Life Science Journal, v.11, n. 6, p. 636-645, 2014.

BARDIN, L. Análise de conteúdo. Lisboa: Edições 70, 1977.

BARROS, A. J. S.; LEHFELD, N. A. S. Fundamentos de metodologia científica. 3. ed. São Paulo, 2007.

BATISTA, F. F. Modelo de gestão do conhecimento para a administração pública brasileira: como implementar a gestão do conhecimento para produzir resultados em benefício do cidadão. Instituto de Pesquisa Econômica Aplicada - IPEA. 2012. Disponível em: <http://repositorio.ipea.gov.br/handle/11058/754>. Acesso em: 31 jul. 2017.

BEHRENS, M. A. A prática pedagógica e o desafio do paradigma emergente. Revista Brasileira de Estudos Pedagógicos, v. 80, n. 196, p. 383-403, 2007.

BEM, R. M.; COELHO, C. C. S. R.; DANDOLINI, G. A. Knowledge management framework to the university libraries. Library Management, v. 37, n. 4/5, p. 221-236, 2016. DOI http://dx.doi.org/10.1108/LM-01-2016-0005

BOLISANI, E.; HANDZIC, M. (Ed.). Advances in knowledge management: celebrating twenty years of research and practice. Springer, 2015.

BUENO, G. S. et al. Gestão estratégia do conhecimento. Revista FAE, v. 7, n. 1, p. 89 - 102, 2004.

BUKOWITZ, W. R.; WILLIAMS, R. L. Manual de gestão do conhecimento: ferramentas e técnicas que criam valor para a empresa. São Paulo: Bookman, 2002.

BURMESTER, H. Manual de gestão: organização, processos e práticas de liderança. São Paulo: Saraiva, 2012.

Perspectivas em Gestão \& Conhecimento, João Pessoa, v. 9, n. 2, p. 174-202, maio/ago. 2019. 
CAPRA, F. A teia da vida: uma nova compreensão científica dos sistemas vivos. 9 ed. São Paulo: Cultrix, 2000

CASTILLO, L. A. M.; CAZARINI, E. W. Integrated model for implementation and development of knowledge management. Knowledge Management Research \& Practice, v. 12, n. 2, p. $145-$ 160, 2014. DOI http://dx.doi.org/10.1057/kmrp. 2012.49.

CHANDLER, A. Strategy and Structure, MIT Press, Cambrige, MA, 1962.

CREMA, R. Abordagem holística: integração do método analítico e sintético. In: BRANDÃO, D.; CREMA, R. (orgs). O novo paradigma holístico: ciência, filosofia, arte e mística. São Paulo: Summus, p. 83-99, 1991.

CREMA, R. Introdução à visão holística: breve relato de viagem do velho ao novo paradigma. 6 ed. São Paulo: Summus, 2015 [livro eletrônico].

DAVENPORT, T. H. Ecologia da informação: porque só a tecnologia não basta para o sucesso na era da informação. São Paulo: Futura, 1998.

DAVENPORT, T. H.; DE LONG, D. W.; BEERS, M. C. Successfull knowledge management projects. Sloan Management Review, v.39, n. 2, p. 43-57, 1998.

DAVENPORT, T. H.; VÖLPEL, S. C. The rise of knowledge towards attention management. Journal of Knowledge Management, v. 5, n. 3, p. 212-221, 2001.

DRESCH, A.; LACERDA, D. P.; ANTUNES JÚNIOR, J. A. V. Design science research: método de pesquisa para avanço da ciência e tecnologia. Bookman Editora, 2015.

FERREIRA, V. C. P. et al. Modelos de gestão. 3 ed. Rio de Janeiro: Editora FGV, 2009.

FLEURY, M. T. L. Cultura organizacional: os modismos, as pesquisas, as intervenções: uma discussão metodológica. Revista de Administração de Empresas. São Paulo, v. 24, n.1, 1996.

FONSECA, A. F. Organizational knowledge assessment methodology. Washington: World Bank Institute, 2006.

FTEIMI, N. Analyzing the literature on knowledge management frameworks: Towards a normative knowledge management classification schema. In: 23rd European Conference on Information Systems, ECIS 2015, v. 2015-May, 2015. Anais [...]. 23rd European Conference on Information Systems, ECIS 2015, 2015.

FUTAMI, A. H. Um Modelo de Gestão do conhecimento para a melhoria de qualidade do produto. 2001. 156 f. Dissertação (Mestrado em Engenharia de Produçäo) - Programa de PósGraduação em Engenharia de Produção, Universidade Federal de Santa Catarina, 2001. Disponível em: <https://repositorio.ufsc.br/handle/123456789/106507>. Acesso em: 29. mai. 2017.

GAI, S.; XU, C. Research of critical success factors for implementing knowledge management in China. Anais [...]. 2009 International Conference on Information Management, Innovation

Perspectivas em Gestão \& Conhecimento, João Pessoa, v. 9, n. 2, p. 174-202, maio/ago. 2019. 
Management and Industrial Engineering, ICIII 2009, v.4, p. 561-564, 2009. DOI http://dx.doi.org/10.1109/ICIII.2009.594.

GASKELL, G.; BAUER, M. W. Pesquisa qualitativa com texto, imagem e som. Petrópolis: Vozes, p. 137-155, 2002.

GIL, A. C. Métodos e técnicas de pesquisa social. 4. ed. São Paulo: Atlas, 2002.

HEISIG, P. Harmonisation of knowledge management - comparing $160 \mathrm{KM}$ frameworks around the globe. Journal of knowledge management, v. 13, n. 4, p. 4-31, 2009. DOI https://doi.org/10.1108/13673270910971798.

HOFER, C. W.; SCHENDEL, D. Strategy formulation: Analytical concepts. West Publ., 1978.

HOLSAPPLE, C. W.; JOSHI, K. D. An investigation of factors that influence the management of knowledge in organizations. The Journal of Strategic Information Systems, v. 9, n. 2-3, p. 235261, 2000. DOI http://dx.doi.org/10.1016/S0963-8687(00)00046-9.

HOLSAPPLE, C. W.; JOSHI, K. D. Description and analysis of existing knowledge management frameworks. In: Systems Sciences, 1999. HICSS-32. Anais [...]. Proceedings of the 32nd Annual Hawaii International Conference on. IEEE, p. 15, 1999. DOI https://doi.org/10.1109/HICSS.1999.772796.

HOLSAPPLE, C. W.; JOSHI, K. D. A formal knowledge management ontology: conduct, activities, resources, and influences, Journal of the American Society for Information Science and Technology, v. 55, n. 7, p. 593-612, 2004.

JAUCH, L. R.; GLUECK, W. F. Business policy and strategic management. McGraw-Hill, 1988.

JUNIOR, A. S.; POLIZEL, C. E. G.; SILVA, P. O. M. Critical success factors for knowledge management at a private higher education school. Revista Brasileira de Gestão de Negocios, v.14, n. 42, p. 102-122, 2012.

KATZ, R. L. Cases and concepts in corporate strategy, Prentice-Hall Inc., New Jersey, 1970.

KUHN, T. S. A estrutura das revoluções científicas. 5ed. São Paulo: Editora Perspectiva, 1998.

KUMAR, S.; SINGH, V.; HALEEM, A. Critical success factors of knowledge management: modelling and comparison using various techniques. International Journal of Industrial and Systems Engineering, v.21, n. 2, p. 180-206, 2015. DOI http://dx.doi.org/10.1504/IJISE.2015.071508.

LACERDA, R. T. O.; ENSSLIN, L.; ENSSLIN, S. R. Uma análise bibliométrica da literatura sobre estratégia e avaliação de desempenho. Gestão \& Produção, v. 19, n. 1, 2012.

LAVILLE, C.; DIONNE, J. A construção do saber: manual de metodologia da pesquisa em ciências humanas. Artmed; UFMG, 1999.

LEARNED E. P. et al. Business Policy: text and cases. Richard D. Irwin. 1965.

Perspectivas em Gestão \& Conhecimento, João Pessoa, v. 9, n. 2, p. 174-202, maio/ago. 2019. 
LIN, Y-C.; LIN, L-K. Critical success factors for knowledge management studies in construction. 2006. Anais [...]. Proceedings of the 23rd International Symposium on Robotics and Automation in Construction, ISARC 2006, p. 768-772, 2006.

MACIEL, C.; SILVA, A. Gerenciando pessoas utilizando modelos holísticos. Revista da Administração Contemporânea - RAC, v. 12, n. 1, p. 35-58, 2008 . DOI http://dx.doi.org/10.1590/S1415-65552008000100003.

MARCONI, M. A.; LAKATOS, E. M. Fundamentos de metodologia científica. 5. ed. São Paulo: Atlas, 2003.

MASCARENHAS, S. A. Metodologia científica. São Paulo: Pearson Education do Brasil, 2012.

MENDES, S. P. Prática motivacional de compartilhamento do conhecimento organizacional em portais corporativos. In: CARVALHO, I. M.; MENDES, S. P.; VERAS, V. M. (orgs). Gestão do conhecimento: uma estratégia empresarial. Brasília: J. J. Gráfica e Comunicações, 2006, p. 130157.

MINAYO, M. C. S. O desafio do conhecimento: pesquisa qualitativa em saúde. 5. ed. São Paulo: Hucitec, 1998.

MINTZBERG, H. et al. Safári de estratégia: um roteiro pela selva do planejamento estratégico. Porto Alegre: Bookman, 2000.

MINTZBERG, H. Opening up the definition of strategy. In: QUINN, J. B.; MINTZBERG, H.; JAMES, R.M. (eds). The strategic process - concepts, contexts and cases. Prentice-Hall Inc, 1988.

MINTZBERG, H.; AHLSTRAND, B.; LAMPEL, J. Safári da estratégia. 2. ed. Bookman Editora: Porto Alegre, 2010.

MORIN, E. Ciência com consciência. 8. ed. Rio de Janeiro: Bertrand Brasil, 2005.

NAGHAVI, M.; DASTAVIZ, A. H.; NEZAKATI, H. Relationships among critical success factors of knowledge management and organizational performance. Journal of Applied Sciences, v.13, n. 5, p. 755-759, 2013. DOI http://dx.doi.org/10.3923/jas.2013.755.759.

NICOLAU, I. O Conceito da Estratégia. Instituto para o Desenvolvimento da Gestão Empresarial - INDEG/ISCTE, 2001.2 Disponível em: $<$ http://cedo.ina.pt/docbweb/MULTIMEDIA/ASSOCIA/INTERNO/ELECTRON/E160.PDF>. Acesso em 28 ago. 2017.

NONAKA, I.; TAKEUCHI, H. Criação de conhecimento na empresa: como as empresas japonesas geram a dinâmica da inovação. 10 ed. Rio de Janeiro: Editora Campus, 1997.

OLIVEIRA, L. A estratégia organizacional na competitividade: um estudo teórico. Revista eletrônica de administração, v. 10, n. 4, 2004.

OSINSKI, M.; ROMAN, D. J.; SELIG, P. M. Compartilhamento de conhecimento: estudo bibliométrico das publicações acadêmicas realizadas de 1994 a 2014. Perspectivas em Ciência da Informação, v. 20, n. 4, p. 149-162, 2015.

Perspectivas em Gestão \& Conhecimento, João Pessoa, v. 9, n. 2, p. 174-202, maio/ago. 2019. 
PEREIRA, H. J.; SKROBOT, L. C.; DANIELSSON, M. Gestão do conhecimento: um modelo corporativo integrado com foco na competitividade e sustentabilidade organizacional. In: RODRIGUEZ, M. V. R. y (org). Gestão do conhecimento e inovação nas empresas. Rio de Janeiro: Qualitymark Editora, p. 213-233, 2010.

PEREIRA, M. F. A gestão organizacional em busca do comportamento holístico. In: ANGELONI, M. T. (org.). Organizações do conhecimento: infra-estrutura, pessoas e tecnologia. São Paulo: Saraiva, p. 2-28, 2002.

PESTANA, M. C. et al. Desafios da sociedade do conhecimento e gestão de pessoas em sistemas de informação. Ciência da Informação, v. 32, n. 2, 2003.

PIRAQUIVE, F. N. D.; GARCÍA, V. H. M.; CRESPO, R. Knowledge management model for project management. In: International Conference on Knowledge Management in Organizations, 10., 2015. Slovênia. Anais... Maribor: Slovênia, 2015. p. 235-247. DOI http://dx.doi.org/10.1007/978-3-319-21009-4 18.

PROBST, G.; RAUB, S., ROMHARDT, K. Gestão do conhecimento: os elementos construtivos do sucesso. Porto Alegre: Bookman, 2002.

QUINN, J. B. Strategies for change: logical incrementalism. Irwin Professional Publishing, 1980. RAMANANTSOA, B. Voyage en strategie. Revue Française de Marketing, v. 4, p. 21-33, 1984.

REZENDE, Y. Informação para negócios: os novos agentes do conhecimento e a gestão do capital intelectual. Ciência da Informação, v. 31, n. 1, p. 75-83, 2002.

ROCKART, J. F. Chief executives define their own data needs, Harvard Business Review, v. 57, n. 2, p. 81-93, 1979.

RUBENSTEIN-MONTANO, B. et al. A systems thinking framework for knowledge management. Decision support systems, v. 31 , n. 1, p. 5-16, 2001. DOI https://doi.org/10.1016/S01679236(00)00116-0.

SALZANO, K. et al. A Knowledge management framework and approach for clinical development. Therapeutic Innovation \& Regulatory Science, v. 50, n. 5, p. 536-545, 2016. DOI http://dx.doi.org/10.1177/2168479016664773.

SÁNCHEZ, I. R. A.; PONJUÁN DANTE, G. Diseño de un modelo de gestión de conocimiento para entornos virtuales de aprendizaje en salud. Revista Cubana de Información en Ciencias de la Salud, v. 27, n. 2, p. 138-153, 2016.

SANTOS, R. B. P. Modelo de gestão do conhecimento: um estudo de caso aplicado aos processos administrativos de engenharia de uma construtora de médio porte. 2015. $207 \mathrm{f}$. Dissertação (Mestrado em Engranharia Civil) Escola de Engenharia Civil, Universidade Federal de Santa Catarina - UFSC, Florianópolis, 2015.

SEDIGHI, M.; ZAND, F. Knowledge management: Review of the Critical Success Factors and development of a conceptual classification model. Anais [...]. International Conference on ICT and Knowledge Engineering, p. 1-9, 2012. DOI http://dx.doi.org/10.1109/ICTKE.2012.6408553

Perspectivas em Gestão \& Conhecimento, João Pessoa, v. 9, n. 2, p. 174-202, maio/ago. 2019. 
SKYRME, D.; AMIDON, D. The knowledge agenda. Journal of Knowledge Management, v.1, $n$. 1, p. 27-37, 1997. DOI http://dx.doi.org/http://dx.doi.org/10.1108/13673279710800709

TEIXEIRA FILHO, J. Gerenciando conhecimento. 2. ed. Rio de Janeiro: SENAC, 2000.

TERRA, J. C. C. Gestão do conhecimento: o grande desafio empresarial. 5 ed. Rio de Janeiro: Elsevier, 2005a.

TERRA, J. C. C. Gestão do conhecimento: o grande desafio empresarial. Biblioteca Terra Fórum Consultores, p.1-6, 2005b. Disponível em: <https://xa.yimg.com/kq/groups/20665047/336673818/name/Gestao Biblioteca Terra Foru m.pdf>. Acesso em: 29 ago. 2017.

VALMOHAMMADI C. Investigation and assessment of critical success factors of knowledge management implementation in Iranian small-to-medium sized enterprises. Journal of Applied Sciences, v.10, n. 19, p. 2290-2296, 2010.

VERGARA, S. C. Sobre a intuição na tomada de decisão. Cadernos EBAP, n. 62, 1993.

WAI, Y. M.; HONG, A. N. H.; DIN, S. B. Critical success factors and perceived benefits of knowledge management implementation: Towards a conceptual framework. Australian Journal of Basic and Applied Sciences, v.5, n. 10, p. 754-760, 2011.

WEBER, F. et al. Standardisation in knowledge management - towards a common KM framework in Europe. Anais [...]. Proceedings of UNICOM Seminar "Towards Common Approaches \& Standards in KM. 2002.

WEIL, P. O novo paradigma holístico: ondas a procura do mar. In: BRANDÃO, D.; CREMA, R. (orgs). O novo paradigma holístico: ciência, filosofia, arte e mística. São Paulo: Summus, p. 1438, 1991.

WONG, K. Y. A critical review of knowledge management frameworks. International Journal of Information Technology and Management, v. 4, n. 3, p. 269-289, 2005a. DOI http://dx.doi.org/10.1504/IJITM.2005.006785.

WONG, K. Y. Critical success factors for implementing knowledge management in small and medium enterprises. Industrial Management \& Data Systems, v. 105, n. 3, p. 261-279, 2005b. DOI http://dx.doi.org/10.1108/02635570510590101.

WONG, K. Y; ASPINWALL, E. An empirical study of the important factors for knowledgemanagement adoption in the SME Sector. Journal of Knowledge Management, v.9, n. 3, p. 6482, 2005. DOI http://dx.doi.org/https://doi.org/10.1108/13673270510602773.

ZIEBA, M.; ZIEBA, K. Knowledge management critical success factors and the innovativeness of KIBS companies. Engineering Economics, v.25, n. 4, p. 458-465, 2014. DOI http://dx.doi.org/10.5755/j01.ee.25.4.6494. 
APÊNDICE A - Estudos desconsiderados na aplicação do protocolo de estratégia de pesquisa

\begin{tabular}{|l|c|l|}
\hline Critério de exclusão & Qtde & Referência \\
\hline $\begin{array}{l}\text { 1. Estudos indisponíveis } \\
\text { para download }\end{array}$ & 8 & $\begin{array}{l}\text { Butler e Murphy (2007), Zanjani, Abadi e Zare (2009), Milosz e } \\
\text { Milosz (2010), Sivaramakrishnan (2010), Ansari (2011), Mohaghar, } \\
\text { Zanjani e Nouri (2013), Zieba (2014) e Sedighi et al. (2017). }\end{array}$ \\
\hline $\begin{array}{l}\text { 2. Estudos que não } \\
\text { contenham os } \\
\text { descritores no título }\end{array}$ & 0 & Nenhuma ocorrência. \\
\hline $\begin{array}{l}\text { 3. Estudos duplicados } \\
\text { 4. Estudos que não } \\
\text { fundamentam } \\
\text { teoricamente os FCS } \\
\text { apresentados }\end{array}$ & 1 & $\begin{array}{l}\text { Sedighi et al. (2015). } \\
\text { Alazmi e Zairi (2003), Koumpouros, Nicolosi e Martínez-Sellés } \\
\text { (2006), Rubenstein e Geisler (2007), Chung, Tsai e Hsu (2007), } \\
\text { Menkhoff et al. (2007), Akhavan, Hosnavi e Sanjaghi (2009), Chong } \\
\text { e Lin (2009), Chang et al. (2009), Yang, Yehe e Lee (2010), Faed, } \\
\text { Radmand e Talevski (2010), Abd-Elaziz et al. (2011), Akhavan et al. } \\
\text { (2011), Toloie-Eshlaghy e Akbari-Yusefvand (2011), Liu (2011), } \\
\text { Talebi et al. (2012), Mas-Machuca e Martínez Costa (2012), Junior } \\
\text { e Polizel (2012), Patil e Kant (2012), Ramezani, Fathain e Tajdin } \\
\text { (2013), Patil e Kant (2013), Patil e Kant (2014), Berjis, Shirouyehzad } \\
\text { e Tavakoli (2015), Cahyaningsih, Sensuse e Sari (2016) e } \\
\text { Rohajawati et al. (2016). }\end{array}$ \\
\hline
\end{tabular}

Fonte: Dados da pesquisa. 
APÊNDICE B - Denominações e referências literárias

\begin{tabular}{|c|c|c|}
\hline $\begin{array}{l}\text { Fator crítico } \\
\text { de sucesso }\end{array}$ & Qtde & Denominação e referência \\
\hline $\begin{array}{l}\text { Tecnologia da } \\
\text { informação }\end{array}$ & 19 & $\begin{array}{l}\text { Arquitetura do conhecimento: Akhavan, Jafari e Fathian (2006); } \\
\text { Comunicação entre funcionários: Arif e Shalhoub (2014); } \\
\text { Estrutura de conhecimento padrão e flexível: Davenport, De Long e Beers } \\
\text { (1998); } \\
\text { Infraestrutura de TI: Abbaszadeh, Ebrahimi e Fotouhi (2010); } \\
\text { Múltiplos canais de transferência de conhecimento: Davenport, De Long e } \\
\text { Beers (1998); } \\
\text { Sistema de TI / comunicação: Sedigui e Zand (2012); } \\
\text { Tecnologia da informação: Wong (2005b), Wong e Aspinwall (2005), Al- } \\
\text { Mabrouk (2006), Gai e Xu (2009), Valmohammadi (2010), Altaher (2010), } \\
\text { Anggia et al. (2013), Naghavi, Dastaviz e Nezakati (2013), Arif e Shalhoub } \\
\text { (2014) e Kumar, Singh e Haleem (2015); } \\
\text { Tecnológica: Sedigui e Zand (2012); } \\
\text { Uma infraestrutura tecnológica bem desenvolvida: Skyrme e Amidon } \\
\text { (1997); } \\
\text { Uma visão convincente e arquitetura: Skyrme e Amidon (1997). }\end{array}$ \\
\hline $\begin{array}{l}\text { Liderança e } \\
\text { suporte da } \\
\text { alta } \\
\text { administração }\end{array}$ & 18 & $\begin{array}{l}\text { Apoio da alta administração: Wai, Hong e Din (2011); } \\
\text { Gestão de liderança e suporte: Wong (2005b); } \\
\text { Gestão superior: Gai e Xu (2009); } \\
\text { Liderança de gestão: Al-Mabrouk (2006); } \\
\text { Liderança do conhecimento: Skyrme e Amidon (1997); } \\
\text { Liderança e apoio: Gai e Xu (2009); } \\
\text { Liderança e suporte: Wong e Aspinwall (2005); } \\
\text { Liderança e suporte da alta administração: Abbaszadeh, Ebrahimi e } \\
\text { Fotouhi (2010), Valmohammadi (2010), Zieba e Zieba (2014), Arif e } \\
\text { Shalhoub (2014) e Kumar, Singh e Haleem (2015); } \\
\text { Liderança organizacional: Naghavi, Dastaviz e Nezakati (2013); } \\
\text { Suporte da alta administração: Davenport, De Long e Beers (1998) e Anggia } \\
\text { et al. (2013); } \\
\text { Suporte de gerenciamento / compromisso de alta gerência: Sedigui e Zand } \\
\text { (2012); } \\
\text { Suporte de gerenciamento superior: Lin e Lin (2006); } \\
\text { Suporte e compromisso do CEO: Akhavan, Jafari e Fathian (2006). }\end{array}$ \\
\hline Cultura & 18 & $\begin{array}{l}\text { Compartilhando conhecimento: Sedigui e Zand (2012); } \\
\text { Confiança mútua: Lin e Lin (2006); } \\
\text { Conformidade / individualismo: Sedigui e Zand (2012); } \\
\text { Cultura: Wong (2005b), Wong e Aspinwall (2005), Al-Mabrouk (2006), Gai } \\
\text { e Xu (2009), Naghavi, Dastaviz e Nezakati (2013) e Arif e Shalhoub (2014); } \\
\text { Cultura amigável ao conhecimento: Davenport, De Long e Beers (1998); } \\
\text { Cultura organizacional: Akhavan, Jafari e Fathian (2006), Abbaszadeh, } \\
\text { Ebrahimi e Fotouhi (2010), Altaher (2010), Valmohammadi (2010), Wai, } \\
\text { Hong e Din (2011) e Anggia et al. (2013); }\end{array}$ \\
\hline
\end{tabular}

Perspectivas em Gestão \& Conhecimento, João Pessoa, v. 9, n. 2, p. 174-202, maio/ago. 2019. 


\begin{tabular}{|c|c|c|}
\hline Fator crítico & Qtde & Denominação e referência \\
\hline & & $\begin{array}{l}\text { Sistema amigável para trocar e reutilizar o conhecimento: Lin e Lin (2006) } \\
\text { Uma cultura de criação de conhecimento e compartilhamento: Skyrme e } \\
\text { Amidon (1997). }\end{array}$ \\
\hline Mensuração & 15 & $\begin{array}{l}\text { Auditoria de conhecimento: Akhavan, Jafari e Fathian (2006); } \\
\text { Avaliação comparativa: Valmohammadi (2010) e Sedigui e Zand (2012); } \\
\text { Avaliação do processo de gestão do conhecimento: Lin e Lin (2006); } \\
\text { Desempenho: Gai e Xu (2009); } \\
\text { Foco no conhecimento e iniciativa de gestão do conhecimento: Kumar, } \\
\text { Singh e Haleem (2015); } \\
\text { Link para o desempenho econômico ou o valor da indústria: Davenport, De } \\
\text { Long e Beers (1998); } \\
\text { Medição: Wong (2005b); } \\
\text { Medição de desempenho: Valmohammadi (2010); } \\
\text { Mensuração: Wong e Aspinwall (2005), Al-Mabrouk (2006), Sedigui e Zand } \\
\text { (2012) e Arif e Shalhoub (2014); } \\
\text { Parceria e aliança / fornecedor: Sedigui e Zand (2012); } \\
\text { Performance organizacional: Naghavi, Dastaviz e Nezakati (2013). }\end{array}$ \\
\hline $\begin{array}{l}\text { Treinamento } \\
\text { e educação }\end{array}$ & 14 & $\begin{array}{l}\text { Aprendizagem contínua: Skyrme e Amidon (1997); } \\
\text { Educação e treinamento: Anggia et al. (2013); } \\
\text { Educacional: Sedigui e Zand (2012); } \\
\text { Envolvimento e treinamento dos funcionários: Sedigui e Zand (2012); } \\
\text { Programas de treinamento: Akhavan, Jafari e Fathian (2006); } \\
\text { Propósito e linguagem clara: Davenport, De Long e Beers (1998); } \\
\text { Treinamento e aprendizagem: Arif e Shalhoub (2014); } \\
\text { Treinamento e educação: Wong (2005b), Wong e Aspinwall (2005), Al- } \\
\text { Mabrouk (2006), Gai e Xu (2009), Abbaszadeh, Ebrahimi e Fotouhi (2010), } \\
\text { Valmohammadi (2010) e Kumar, Singh e Haleem (2015). }\end{array}$ \\
\hline Estratégia & 13 & $\begin{array}{l}\text { Definição clara de objetivos e regras: Lin e Lin (2006); } \\
\text { Estratégia: Al-Mabrouk (2006); } \\
\text { Estratégia da gestão do conhecimento: Valmohammadi (2010); } \\
\text { Estratégia de conhecimento: Akhavan, Jafari e Fathian (2006) e Arif e } \\
\text { Shalhoub (2014); } \\
\text { Estratégia e objetivos: Gai e Xu (2009); } \\
\text { Estratégia e propósito: Wong (2005b) e Wong e Aspinwall (2005); } \\
\text { Estratégia gestão do conhecimento: Sedigui e Zand (2012); } \\
\text { Forte link para um imperativo de negócios: Skyrme e Amidon (1997); } \\
\text { Gestão da mudança: Sedigui e Zand (2012); } \\
\text { Planejamento estratégico: Abbaszadeh, Ebrahimi e Fotouhi (2010) e } \\
\text { Altaher (2010). }\end{array}$ \\
\hline $\begin{array}{l}\text { Processos e } \\
\text { atividades }\end{array}$ & 11 & $\begin{array}{l}\text { Armazenamento de conhecimento: Akhavan, Jafari e Fathian (2006); } \\
\text { Compartilhamento de conhecimento: Akhavan, Jafari e Fathian (2006); } \\
\text { Compartilhamento do conhecimento: Naghavi, Dastaviz e Nezakati (2013); }\end{array}$ \\
\hline
\end{tabular}

Perspectivas em Gestão \& Conhecimento, João Pessoa, v. 9, n. 2, p. 174-202, maio/ago. 2019. 


\begin{tabular}{|c|c|c|}
\hline & Qtde & Denominação e referência \\
\hline & & $\begin{array}{l}\text { Processos: Al-Mabrouk (2006); } \\
\text { Processos e atividades: Wong (2005b), Wong e Aspinwall (2005), Gai e Xu } \\
\text { (2009), Abbaszadeh, Ebrahimi e Fotouhi (2010), Valmohammadi (2010) e } \\
\text { Sedigui e Zand (2012); } \\
\text { Processos sistemáticos de conhecimento organizacional: Skyrme e Amidon } \\
\text { (1997). }\end{array}$ \\
\hline Motivação & 11 & $\begin{array}{l}\text { Auxiliares de motivação: Wong (2005b), Wong e Aspinwall (2005), Arif e } \\
\text { Shalhoub (2014) e Zieba e Zieba (2014); } \\
\text { Disposição para compartilhar conhecimento: Lin e Lin (2006); } \\
\text { Estabelecimento de uma estratégia de recompensa: Lin e Lin (2006); } \\
\text { Gratificação e motivação: Valmohammadi (2010); } \\
\text { Incentivos: Gai e Xu (2009); } \\
\text { Motivação: Al-Mabrouk (2006); } \\
\text { Mudança nas práticas motivacionais: Davenport, De Long e Beers (1998); } \\
\text { Sistema de incentivo: Sedigui e Zand (2012). }\end{array}$ \\
\hline $\begin{array}{l}\text { Gestão de } \\
\text { recursos } \\
\text { humanos }\end{array}$ & 9 & $\begin{array}{l}\text { Gestão de recursos humanos: Wong (2005b), Al-Mabrouk (2006), } \\
\text { Abbaszadeh, Ebrahimi e Fotouhi (2010), Valmohammadi (2010), Sedigui e } \\
\text { Zand (2012) e Anggia et al. (2013); } \\
\text { Recursos humanos: Wong e Aspinwall (2005) e Naghavi, Dastaviz e } \\
\text { Nezakati (2013); } \\
\text { Recursos humanos e trabalhadores do conhecimento: Kumar, Singh e } \\
\text { Haleem (2015). }\end{array}$ \\
\hline $\begin{array}{l}\text { Equipe de } \\
\text { gestão do } \\
\text { conhecimento }\end{array}$ & 9 & $\begin{array}{l}\text { Coordenação: Sedigui e Zand (2012); } \\
\text { Estrutura da organização no departamento de gestão do conhecimento: } \\
\text { Lin e Lin (2006); } \\
\text { Estrutura do conhecimento: Arif e Shalhoub (2014); } \\
\text { Infraestrutura de organização: Gai e Xu (2009); } \\
\text { Infraestrutura organizacional: Wong (2005b), Wong e Aspinwall (2005), Al- } \\
\text { Mabrouk (2006) e Valmohammadi (2010); } \\
\text { Infraestrutura técnica e organizacional: Davenport, De Long e Beers (1998). }\end{array}$ \\
\hline $\begin{array}{l}\text { Recursos } \\
\text { (financeiro, } \\
\text { humano, } \\
\text { material, } \\
\text { tempo) }\end{array}$ & 8 & $\begin{array}{l}\text { Investimento financeiro: Sedigui e Zand (2012); } \\
\text { Recursos: Wong (2005b), Wong e Aspinwall (2005), Al-Mabrouk (2006), Gai } \\
\text { e Xu (2009) e Abbaszadeh, Ebrahimi e Fotouhi (2010); } \\
\text { Recursos, infra-estrutura e instalações: Kumar, Singh e Haleem (2015); } \\
\text { Remoção de restrições de recursos: Valmohammadi (2010). }\end{array}$ \\
\hline $\begin{array}{l}\text { Trabalho em } \\
\text { equipe }\end{array}$ & 3 & $\begin{array}{l}\text { Habilidade em trabalho em equipe: Sedigui e Zand (2012); } \\
\text { Rede de especialistas: Akhavan, Jafari e Fathian (2006); } \\
\text { Trabalho em equipe: Wai, Hong e Din (2011). }\end{array}$ \\
\hline Projeto piloto & 1 & Piloto: Akhavan, Jafari e Fathian (2006). \\
\hline
\end{tabular}

\section{\begin{tabular}{|l|l|l} 
Critério de exclusão & Qtde & Referência \\
\hline
\end{tabular}}

Perspectivas em Gestão \& Conhecimento, João Pessoa, v. 9, n. 2, p. 174-202, maio/ago. 2019. 


\begin{tabular}{|c|c|c|}
\hline Critério de exclusão & Qtde & Referência \\
\hline $\begin{array}{l}\text { 1. Estudos indisponíveis } \\
\text { para download }\end{array}$ & 8 & $\begin{array}{l}\text { Butler e Murphy (2007), Zanjani, Abadi e Zare (2009), Milosz e } \\
\text { Milosz (2010), Sivaramakrishnan (2010), Ansari (2011), Mohaghar, } \\
\text { Zanjani e Nouri (2013), Zieba (2014) e Sedighi et al. (2017). }\end{array}$ \\
\hline $\begin{array}{l}\text { 2. Estudos que não } \\
\text { contenham os } \\
\text { descritores no título }\end{array}$ & 0 & Nenhuma ocorrência. \\
\hline 3. Estudos duplicados & 1 & Sedighi et al. (2015). \\
\hline $\begin{array}{l}\text { 4. Estudos que não } \\
\text { fundamentam } \\
\text { teoricamente os FCS } \\
\text { apresentados }\end{array}$ & 24 & $\begin{array}{l}\text { Alazmi e Zairi (2003), Koumpouros, Nicolosi e Martínez-Sellés } \\
\text { (2006), Rubenstein e Geisler (2007), Chung, Tsai e Hsu (2007), } \\
\text { Menkhoff et al. (2007), Akhavan, Hosnavi e Sanjaghi (2009), Chong } \\
\text { e Lin (2009), Chang et al. (2009), Yang, Yehe e Lee (2010), Faed, } \\
\text { Radmand e Talevski (2010), Abd-Elaziz et al. (2011), Akhavan et al. } \\
\text { (2011), Toloie-Eshlaghy e Akbari-Yusefvand (2011), Liu (2011), } \\
\text { Talebi et al. (2012), Mas-Machuca e Martínez Costa (2012), Junior } \\
\text { e Polizel (2012), Patil e Kant (2012), Ramezani, Fathain e Tajdin } \\
\text { (2013), Patil e Kant (2013), Patil e Kant (2014), Berjis, Shirouyehzad } \\
\text { e Tavakoli (2015), Cahyaningsih, Sensuse e Sari (2016) e } \\
\text { Rohajawati et al. (2016). }\end{array}$ \\
\hline
\end{tabular}

Nota: a denominação apresentada corresponde ao trecho do texto traduzido para a língua portuguesa pelos autores desta pesquisa. Assim, cada denominação foi consolidada em um fator crítico de sucesso para o qual este se refere, gerando um ranking de 13 Fatores Críticos de Sucesso a serem considerados na GC. 
APÊNDICE C - Referência literária versus fator

\begin{tabular}{|c|c|c|c|c|c|c|c|c|c|c|c|c|c|}
\hline Referência & 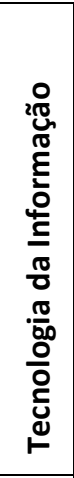 & 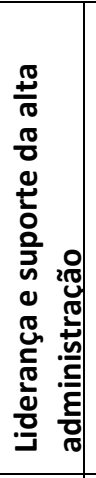 & $\frac{\pi}{3}$ & 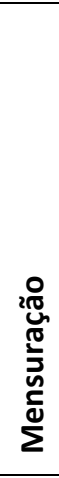 & 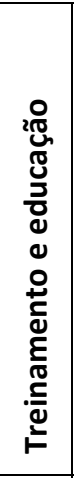 & 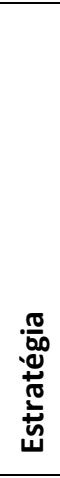 & 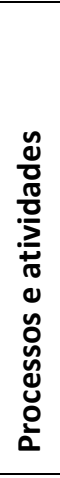 & 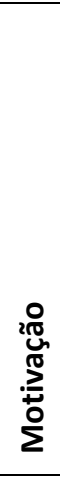 & 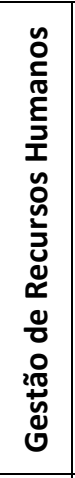 & 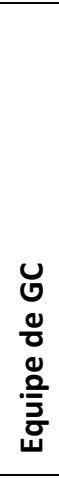 & 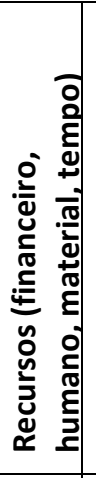 & 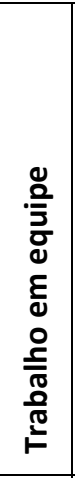 & $\begin{array}{l}\frac{8}{0} \\
\frac{0}{a} \\
0 \\
\frac{d}{0} \\
\frac{0}{2} \\
\frac{0}{2}\end{array}$ \\
\hline $\begin{array}{l}\text { Kumar, Singh e } \\
\text { Haleem (2015) }\end{array}$ & $x$ & $x$ & & $x$ & $x$ & & & & $x$ & & $x$ & & \\
\hline $\begin{array}{l}\text { Arif e Shalhoub } \\
\text { (2014) }\end{array}$ & $x$ & $\mathrm{x}$ & $x$ & $x$ & $\mathrm{x}$ & $\mathrm{x}$ & & $\mathrm{x}$ & & $x$ & & & \\
\hline $\begin{array}{l}\text { Zieba e Zieba } \\
\text { (2014) }\end{array}$ & & $x$ & & & & & & $x$ & & & & & \\
\hline $\begin{array}{l}\text { Naghavi, } \\
\text { Dastaviz e } \\
\text { Nezakati (2013) }\end{array}$ & $x$ & $\mathrm{x}$ & $\mathrm{x}$ & $\mathrm{x}$ & & & $\mathrm{x}$ & & $\mathrm{x}$ & & & & \\
\hline $\begin{array}{l}\text { Anggia et al. } \\
\text { (2013) }\end{array}$ & $x$ & $x$ & $x$ & & $\mathrm{x}$ & & & & $\mathrm{x}$ & & & & \\
\hline $\begin{array}{l}\text { Sedigui e Zand } \\
\text { (2012) }\end{array}$ & $x$ & $x$ & $x$ & $x$ & $x$ & $x$ & $x$ & $x$ & $x$ & $x$ & $x$ & $x$ & \\
\hline $\begin{array}{l}\text { Wai, Hong e Din } \\
\text { (2011) }\end{array}$ & & $x$ & $x$ & & & & & & & & & $x$ & \\
\hline $\begin{array}{l}\text { Abbaszadeh, } \\
\text { Ebrahimi e } \\
\text { Fotouhi (2010) }\end{array}$ & $x$ & $x$ & $x$ & & $x$ & $x$ & $x$ & & $x$ & & $x$ & & \\
\hline Altaher (2010) & $x$ & & $x$ & & & $x$ & & & & & & & \\
\hline $\begin{array}{l}\text { Valmohammadi } \\
(2010)\end{array}$ & $x$ & $x$ & $x$ & $x$ & $\mathrm{x}$ & $x$ & $x$ & $x$ & $x$ & $x$ & $x$ & & \\
\hline Gai e Xu (2009) & $x$ & $x$ & $x$ & $x$ & $\mathrm{x}$ & $x$ & $x$ & $x$ & & $x$ & $x$ & & \\
\hline Lin e Lin (2006) & & $x$ & $x$ & $x$ & & $x$ & & $x$ & & $x$ & & & \\
\hline $\begin{array}{l}\text { Al-Mabrouk } \\
(2006)\end{array}$ & $x$ & $x$ & $x$ & $x$ & $x$ & $x$ & $x$ & $x$ & $x$ & $x$ & $x$ & & \\
\hline $\begin{array}{l}\text { Akhavan, Jafari e } \\
\text { Fathian (2006) }\end{array}$ & $x$ & $\mathrm{x}$ & $x$ & $x$ & $x$ & $x$ & $\mathrm{x}$ & & & & & $x$ & $x$ \\
\hline Wong (2005b) & $x$ & $\mathrm{x}$ & $\mathrm{x}$ & $\mathrm{x}$ & $\mathrm{x}$ & $\mathrm{x}$ & $x$ & $\mathrm{x}$ & $x$ & $\mathrm{x}$ & $x$ & & \\
\hline $\begin{array}{l}\text { Wong e } \\
\text { Aspinwall (2005) }\end{array}$ & $x$ & $\mathrm{x}$ & $\mathrm{x}$ & $\mathrm{x}$ & $x$ & $x$ & $x$ & $x$ & $\mathrm{x}$ & $x$ & $\mathrm{x}$ & & \\
\hline $\begin{array}{l}\text { Davenport, De } \\
\text { Long e Beers } \\
\text { (1998) }\end{array}$ & $\mathrm{x}$ & $\mathrm{X}$ & $\mathrm{x}$ & $\mathrm{x}$ & $x$ & & & $\mathrm{x}$ & & $\mathrm{x}$ & & & \\
\hline $\begin{array}{l}\text { Skyrme e } \\
\text { Amidon (1997) }\end{array}$ & $x$ & $x$ & $x$ & & $x$ & $x$ & $x$ & & & & & & \\
\hline
\end{tabular}

Perspectivas em Gestão \& Conhecimento, João Pessoa, v. 9, n. 2, p. 174-202, maio/ago. 2019. 